\title{
Emerging Therapeutic Options for Chronic Pruritus
}

\author{
Radomir Reszke ${ }^{1} \cdot$ Piotr Krajewski $^{1}$ Jacek C. Szepietowski ${ }^{1}$ (i)
}

Published online: 30 June 2020

(c) The Author(s) 2020

\begin{abstract}
Chronic pruritus, defined as an unpleasant sensation resulting in a need to scratch that lasts more than 6 weeks, is a prevalent and bothersome symptom associated with both cutaneous and systemic conditions. Due to complex pathogenesis and profuse contributing factors, chronic pruritus therapy remains challenging. Regardless of the well-established antipruritic properties of classic pharmacotherapy (topical therapy, phototherapy and systemic therapy), these methods often provide insufficient relief for affected individuals. Owing to the growing interest in the field of pruritic research, further experimental and clinical data have emerged, continuously supporting the possibility of instigating novel therapeutic measures. This review covers the most relevant current modalities remaining under investigation that possess promising perspectives of approval in the near future, especially opioidergic drugs (mu-opioid antagonists and kappa-opioid agonists), neurokinin-1 receptor antagonists, biologic drugs, Janus kinase inhibitors, ileal bile acid transporter inhibitors, aryl hydrocarbon receptor agonists and histamine $\mathrm{H}_{4}$ receptor antagonists.
\end{abstract}

\section{Key Points}

Chronic pruritus $(\mathrm{CP})$ is a frequent symptom stemming from dermatologic and systemic conditions, which is associated with a significant negative impact on quality of life.

The management of $\mathrm{CP}$ remains challenging despite a plethora of modalities, which can be classified as topical therapy, phototherapy and systemic therapy.

With the growing understanding of CP pathogenesis and the increasing quality of data derived from clinical trials, novel therapeutic measures have emerged and are soon to be included in the antipruritic armamentarium of dermatologists in everyday practice. Prominent examples are opioidergic drugs, neurokinin-1 receptor antagonists, biologic drugs targeting various cytokines and Janus kinase inhibitors, to name just a few.

Jacek C. Szepietowski

jacek.szepietowski@umed.wroc.pl

1 Department of Dermatology, Venereology and Allergology, Wroclaw Medical University, 1 Chalubinskiego Street, 50-368 Wrocław, Poland

\section{Introduction}

Chronic pruritus (CP), defined as an unpleasant sensation resulting in a need to scratch that lasts more than 6 weeks, is a prevalent and bothersome symptom associated with cutaneous conditions (such as psoriasis, atopic dermatitis [AD], lichen planus [LP], etc.); however, primarily extracutaneous ailments may also play a role in the occurrence of $\mathrm{CP}[1$, 2]. Prominent examples of the latter include end-stage renal disease (ESRD), diabetes mellitus, hypothyroidism, chronic hepatobiliary conditions, or malignancies, to name just a few. The etiology of CP may be comprehensively classified as dermatologic, systemic, neurologic, psychogenic, mixed or unknown. Therefore, physicians other than dermatologists also frequently encounter this phenomenon in both outpatient and clinical settings. The burden of CP stems from a marked decrease in various domains of health-related quality of life (HRQoL) [3-5].

The pathogenesis of CP is particularly complex. Two major neuronal pathways are mentioned: histaminergic and non-histaminergic, with the latter mainly associated with $\mathrm{CP}$ [6]. $\mathrm{CP}$ in the course of $\mathrm{AD}$ (serving as an example of a 'classic' itchy disorder) may be regarded as a result of crosstalk between nervous system, cutaneous immune system and keratinocyte populations [7]. The crucial pathogenetic aspects of $\mathrm{CP}$, such as the interactions between various pruritogens and their receptors, and the description of itch pathways with regard to peripheral nervous system (PNS) 
and central nervous system (CNS) processing in different regions, including neural sensitization, have been reviewed in great detail by Yosipovitch et al. [6,7].

Despite the abundance of therapeutic measures, the alleviation of $\mathrm{CP}$ remains challenging. According to expert consensus, the therapeutic measures may be divided into several groups: general recommendations (including frequent application of emollients), topical therapy (e.g. corticosteroids, calcineurin inhibitors, crisaborole), phototherapy and systemic therapy [2]. The latter is usually reserved for patients with the most severe symptoms. Currently, the majority of antipruritic modalities are still utilized off-label. The detailed characteristics of well-established antipruritic modalities lie beyond the scope of this review and are described in detail elsewhere. Owing to the growing interest in the field of pruritic research, further experimental and clinical data emerge, continuously supporting the possibility of instigating novel therapeutic measures. This review covers the most relevant current drugs, predominantly remaining under investigation, with promising perspectives of approval in the near future, especially opioidergic drugs (mu-opioid antagonists and kappa-opioid agonists), neurokinin-1 receptor (NK-1R) antagonists, biologic drugs, Janus kinase (JAK) inhibitors, ileal bile acid transporter (IBAT) inhibitors, aryl hydrocarbon receptor (AhR) agonists and histamine receptor type 4 antagonists, as well as other modalities (Table 1).

\section{Opioid Receptor Agonists and Antagonists}

An endogenous opioid system is associated with numerous functions in the organism, with its key elements constituting endogenous opioid peptides ( $\beta$-endorphin, enkephalins and dynorphins) and opioid receptors (mu, kappa, delta and nociceptin/orphanin FQ receptor (NOP-R)), which are especially prevalent in the CNS, PNS and the skin [8-10]. Exogenous opioids implemented in clinical practice may stimulate pruritic responses in an individual, mostly as adverse effects (AEs) of epidural, intraspinal or intrathecal administration [11]. Relevant studies performed on primates revealed not only that mu-opioid agonists induced pruritus but also the sensation was relieved following the administration of mu-opioid antagonists or kappa-opioid agonists [12-14]. In fact, decreased expression of kappa-opioid receptors in human skin was associated with pruritus in the course of AD [15], psoriasis [16, 17] and ESRD [18]. Throughout the years, several drugs targeting opioid receptors have revealed certain antipruritic properties, especially as a preoperative prophylaxis, as well as in uremic pruritus (UP) or cholestatic pruritus (CP). 'Classic' antipruritics with predominant mu-opioid antagonist activity comprised naloxone [19-21], naltrexone [22-25] and nalmefene [26, 27]. Drugs possessing mixed mu-opioid antagonism and kappa-opioid agonism (butorphanol, nalbuphine) also alleviated itch in a variety of conditions [28-32].

\subsection{Nalbuphine}

A recent phase II/III randomized, double-blind trial on nalbuphine was performed in patients with UP [33]. Nalbuphine in extended-release tablets was administered orally in 128 and 120 patients (starting with 60 and $120 \mathrm{mg} / \mathrm{day}$, respectively, and later increasing to 120 and $240 \mathrm{mg} / \mathrm{day}$, respectively), while 125 patients received placebo. The mean changes from baseline Worst Itch Numeric Rating Scale (WI-NRS) score (6.8-6.9 points) were $-3.1,-3.5$ and -2.8 points, respectively; $p=0.017$ compared with placebo. In patients with a baseline NRS score of at least 7.0 points (mean 8.0 points), nalbuphine $240 \mathrm{mg} /$ day provided better WI-NRS score alleviation than placebo $(-4.5$ vs. -3.2 ; $p<0.01)$. Nalbuphine was also successfully evaluated in patients with chronic prurigo $(n=62)$ [34], and the results of a further phase IIb/III study on 240 participants (PRISM) are awaited in 2020 [35].

\subsection{Nalfurafine}

Nalfurafine possesses a selective kappa-opioid agonism and currently remains the only drug registered for the treatment of UP and CP (exclusively in Japan). Its properties have been initially confirmed in 144 hemodialysis patients with pruritus who experienced a higher number of days with nondisturbing itching and number of nights with good sleep after intravenous administration [36]. Subsequent studies on nalfurafine administered orally supported its effectiveness and safety in managing UP [37-39], including patients on peritoneal dialysis [40]. Notably, a postmarketing surveillance study was conducted in 3762 patients on hemodialysis, revealing good antipruritic response within 12 weeks in $82.5 \%$ of patients [41]. Recent studies have also evaluated nalfurafine as a drug potentially ameliorating pruritus due to chronic liver diseases [42, 43]. Unfortunately, a preliminary study suggested that within 4 weeks of nalfurafine discontinuation there is a $100 \%$ risk of pruritus recurrence [44]. Moreover, excluding the initial study by Wikström et al. [36], several subsequent studies have concordantly mentioned insomnia as the most common $\mathrm{AE}$ associated with nalfurafine intake [37, 38, 40, 41].

\subsection{Difelikefalin}

Another compound currently receiving growing interest, difelikefalin (CR845), is selective towards peripheral kappa-opioid receptors in the skin as it is not able to cross the blood-brain barrier [45]. In a phase II randomized trial among subjects with UP, difelikefalin was administered intravenously (after a 
Table 1 Emerging drugs with antipruritic properties

\begin{tabular}{|c|c|c|c|c|}
\hline Drug name & Mechanism of action & Route of administration & Indications & References \\
\hline \multicolumn{5}{|c|}{ Mu-opioid antagonists/kappa-opioid agonists } \\
\hline Nalbuphine & $\begin{array}{l}\text { Mu-opioid antagonist, } \\
\text { kappa-opioid agonist }\end{array}$ & Intravenous, oral & UP, chronic prurigo & {$[33-35]$} \\
\hline Nalfurafine & Kappa-opioid agonist & Intravenous, oral & UP, cholestatic pruritus & {$[36-44]$} \\
\hline Difelikefalin & $\begin{array}{l}\text { Kappa-opioid agonist } \\
\text { (peripheral) }\end{array}$ & Intravenous, oral ${ }^{\mathrm{a}}$ & $\mathrm{UP}, \mathrm{PBC}^{\mathrm{a}}$ & [46-49] \\
\hline \multicolumn{5}{|l|}{ NK-1R antagonists } \\
\hline Aprepitant & NK-1R antagonist & Oral & $\begin{array}{l}\text { Pruritus in Sezary syndrome } \\
\text { Pruritus in solid tumors } \\
\text { Pruritus due to antitumor } \\
\text { therapies } \\
\text { Chronic prurigo }\end{array}$ & {$[54-59]$} \\
\hline Serlopitant & NK-1R antagonist & Oral & $\begin{array}{l}\text { Chronic prurigo, psoriasis, } \\
\text { epidermolysis bullosa }^{\mathrm{a}}\end{array}$ & {$[60,61,65,67]$} \\
\hline Tradipitant & NK-1R antagonist & Oral & $\mathrm{AD}$ & {$[68,70]$} \\
\hline \multicolumn{5}{|l|}{ Biologic drugs } \\
\hline \multicolumn{5}{|l|}{ IL-13 antagonists } \\
\hline Dupilumab & IL-4 and IL-13 antagonist & Subcutaneous & $\begin{array}{l}\mathrm{AD} \text {, urticaria, chronic pru- } \\
\text { rigo, } \mathrm{BP} \text {, chronic refractory } \\
\text { pruritus }\end{array}$ & [79-97] \\
\hline Lebrikizumab & IL-13 antagonist & Subcutaneous & $\mathrm{AD}$ & {$[100,101]$} \\
\hline Tralokinumab & IL-13 antagonist & Subcutaneous & $\mathrm{AD}^{\mathrm{a}}$ & [103-106] \\
\hline \multicolumn{5}{|l|}{ IL-17 antagonists } \\
\hline Secukinumab & IL-17A antagonist & Subcutaneous & Psoriasis, $\mathrm{AD}^{\mathrm{a}}$ & {$[111-114,243,244]$} \\
\hline Ixekizumab & IL-17A antagonist & Subcutaneous & Psoriasis & {$[116-118,123,245-247]$} \\
\hline Brodalumab & IL-17A receptor antagonist & Subcutaneous & Psoriasis & {$[120]$} \\
\hline \multicolumn{5}{|l|}{ IL-23 antagonists } \\
\hline Ustekinumab & IL-12 and IL-23 antagonist & Subcutaneous & Psoriasis & {$[123,129]$} \\
\hline Risankizumab & IL-23 antagonist & Subcutaneous & Psoriasis, $\mathrm{AD}^{\mathrm{a}}$ & {$[124,248]$} \\
\hline Guselkumab & IL-23 antagonist & Subcutaneous & Psoriasis & {$[129,247,249]$} \\
\hline Tildrakizumab & IL-23 antagonist & Subcutaneous & Psoriasis $^{\mathrm{a}}$ & [132-136] \\
\hline \multicolumn{5}{|c|}{ Drugs targeting the IL-31 pathway } \\
\hline Nemolizumab & IL-31RA antagonist & Subcutaneous & $\mathrm{AD}$, chronic prurigo & {$[139,140,250-254]$} \\
\hline Vixarelimab (KPL-716) & OSMR $\beta$ antagonist & Subcutaneous & $\begin{array}{l}\text { AD, chronic pruritic disor- } \\
\text { ders (chronic idiopathic } \\
\text { urticaria, chronic idi- } \\
\text { opathic pruritus, LP, lichen } \\
\text { simplex chronicus, plaque } \\
\text { psoriasis), }{ }^{a} \text { chronic prurigo }\end{array}$ & {$[141-143]$} \\
\hline \multicolumn{5}{|l|}{$\operatorname{IgE}$ antagonists } \\
\hline Ligelizumab & $\begin{array}{l}\text { IgE antagonist (targets free } \\
\text { IgE, FceRI and surface } \\
\text { IgE) }\end{array}$ & Subcutaneous & $\begin{array}{l}\text { Chronic spontaneous urti- } \\
\text { caria }\end{array}$ & {$[145]$} \\
\hline \multicolumn{5}{|l|}{ JAK inhibitors } \\
\hline Ruxolitinib & JAK inhibitor & Topical, oral & $\begin{array}{l}\text { AD, polycythemia vera, } \\
\text { essential thrombocytosis, } \\
\text { primary myelofibrosis, } \mathrm{LP},{ }^{\mathrm{a}} \\
\text { cGvHD }^{\mathrm{a}}\end{array}$ & [149-157] \\
\hline Baricitinib & JAK inhibitor & Oral & $\mathrm{AD}$, psoriasis & {$[158-164]$} \\
\hline Tofacitinib & JAK inhibitor & Oral, topical & Psoriasis, AD & {$[166-174]$} \\
\hline Abrocitinib & JAK inhibitor & Oral & $\mathrm{AD}$ & {$[175-179]$} \\
\hline Upadacitinib & JAK inhibitor & Oral & $\mathrm{AD}$ & [181-186] \\
\hline Delgocitinib & JAK inhibitor & Topical & Chronic hand eczema, AD & [188-191] \\
\hline
\end{tabular}


Table 1 (continued)

\begin{tabular}{|c|c|c|c|c|}
\hline Drug name & Mechanism of action & Route of administration & Indications & References \\
\hline \multicolumn{5}{|l|}{ PDE-4 inhibitors } \\
\hline Crisaborole & PDE-4 inhibitor & Topical & $\mathrm{AD}$ & [193-195] \\
\hline \multicolumn{5}{|l|}{ TrkA inhibitors } \\
\hline $\begin{array}{l}\text { Pegcantratinib (CT327; } \\
\text { SNA-120) }\end{array}$ & $\begin{array}{l}\text { TrkA inhibitor (NGF path- } \\
\text { way inhibition) }\end{array}$ & Topical & Psoriasis & {$[197,198]$} \\
\hline \multicolumn{5}{|l|}{ IBAT inhibitors } \\
\hline Linerixibat & IBAT inhibitor & Oral & Cholestatic pruritus & [205] \\
\hline Odevixibat & IBAT inhibitor & Oral & Cholestatic pruritus & [206] \\
\hline Maralixibat & IBAT inhibitor & Oral & Cholestatic pruritus & {$[203,204]$} \\
\hline \multicolumn{5}{|l|}{ AhR agonists } \\
\hline Tapinarof (GSK2894512) & AhR agonist & Topical & $\mathrm{AD}$ & {$[213]$} \\
\hline \multicolumn{5}{|l|}{$\mathrm{H}_{4} \mathrm{R}$ antagonists } \\
\hline Adriforant (ZPL-3893787) & $\mathrm{H}_{4} \mathrm{R}$ antagonist & Oral & $\mathrm{AD}$ & {$[220-222]$} \\
\hline
\end{tabular}

$A D$ atopic dermatitis, $A h R$ aryl hydrocarbon receptor, $B P$ bullous pemphigoid, $c G v H D$ chronic cutaneous graft-versus-host disease, $H_{4} R$ histamine $\mathrm{H}_{4}$ receptor, $I B A T$ ileal bile acid transporter, $I G$ immunoglobulin, $I L$ interleukin, $L P$ lichen planus, $J A K$ Janus kinase, $N G F$ nerve growth factor, $N K-1 R$ neurokinin-1 receptor, $O S M R \beta$ oncostatin M receptor beta, $P B C$ primary biliary cholangitis, $P D E-4$ phosphodiesterase-4, TrkA tropomyosin-receptor kinase $\mathrm{A}, U P$ uremic pruritus

${ }^{a}$ Indications currently under investigation

hemodialysis session) thrice weekly for 8 weeks in doses of $0.5,1.0$ or $1.5 \mathrm{mg} / \mathrm{kg}$ to 44,42 and 44 patients, respectively, while 45 patients received placebo [46]. At week 8, patients receiving difelikefalin were significantly more prone to experience alleviation of pruritus (at least -3 points in the WI-NRS) when compared with placebo ( $59 \%$ vs. $29 \%$; $p=0.001$ ), as well as significant improvement in itch-related QoL. The reduction from the baseline Skindex-10 total score at week 8 was -16.4 and -8.2 , respectively $(p<0.001)$. Moreover, the active group reported less problems with sleep, as measured by the Medical Outcomes Study sleep disturbance questionnaire $(p=0.005)$. A further double-blind, placebo-controlled, phase III trial (KALM-1) encompassed 189 patients receiving difelikefalin $(0.5 \mathrm{mg} /$ day intravenously after hemodialysis $)$ and 188 patients receiving placebo [47]. Significantly more patients receiving difelikefalin experienced at least 3 points of improvement in pruritus at week 12 , as measured by the WI-NRS (49.1\% vs. $27.9 \%$; $p<0.001)$. The most common AEs were diarrhea, dizziness and nausea/vomiting [46, 47]. Notably, the beneficial WI-NRS response of difelikefalin started to unveil after 1 week of treatment. The results of further studies on oral difelikefalin, especially in UP [48] and primary biliary cholangitis (PBC) [49], are highly anticipated.

\section{Neurokinin-1 Receptor Antagonists}

Substance P (SP) belongs to the group of tachykinins, which are small neuropeptides released by neurons and inflammatory cells [50]. SP binds to NK-1R, as well as the
Mas-related G protein-coupled receptor (Mrgpr). NK-1R is more substantiated in eliciting pruritic response in humans as it induces vasodilatation, degranulation of mast cells, nerve growth factor (NGF) expression in keratinocytes and stimulates neurogenic inflammation [51]. In the study by Nattkemper et al. [52], the authors utilized RNA sequencing and observed increased levels of both SP and NK-1R in lesional skin of patients with psoriasis and $\mathrm{AD}$ who experienced severe pruritus.

\subsection{Aprepitant}

Aprepitant is an oral NK-1R antagonist that is currently registered for the prevention of chemotherapy-induced and postoperative nausea and vomiting [53]. Aprepitant demonstrated antipruritic activities in patients with Sezary syndrome, solid tumors and those receiving antitumoral drugs such as epidermal growth factor receptor inhibitors (EGFRIs) and tyrosine kinase inhibitors [54-57]. In a German study, 20 patients with chronic refractory pruritus (due to systemic and mixed causes) received aprepitant $80 \mathrm{mg} /$ day for 3-13 days (mean 6.6 days) [58]. Eighty percent of patients $(16 / 20)$ responded to the regimen. Agelopoulos et al. [59] recently reported on the usefulness of aprepitant in chronic prurigo. Of 12 patients receiving aprepitant ( $80 \mathrm{mg} /$ day), the mean visual analog scale (VAS) pruritus score decreased from $6.3 \pm 1.3$ points at baseline to $4.5 \pm 2.9$ points after 8 weeks $(p<0.05)$. 


\subsection{Serlopitant}

Two phase II studies on a novel oral NK-1R antagonist, serlopitant, were also reported. Yosipovitch et al. [60] utilized serlopitant among patients with CP refractory to standard treatment in doses of $0.25 \mathrm{mg} /$ day $(n=64), 1 \mathrm{mg} /$ day $(n=65)$ and $5 \mathrm{mg} /$ day $(n=64)$, whereas 64 patients received placebo. On the first day of treatment, patients in the active groups received loading doses of either $0.75 \mathrm{mg} /$ day, $3 \mathrm{mg} /$ day or $15 \mathrm{mg} /$ day. At week 6 , the mean percentage decreases from baseline in terms of VAS pruritus score were statistically significantly greater in the $1 \mathrm{mg} /$ day $(p=0.02)$ and $5 \mathrm{mg} /$ day $(p=0.01)$ groups when compared with the placebo group. Moreover, the beneficial effects remained 4 weeks after the completion of treatment. In the study by Ständer et al. [61], serlopitant ( $5 \mathrm{mg} / \mathrm{day}$; on the first day patients received a loading dose of $15 \mathrm{mg} /$ day) was administered to 65 patients with chronic prurigo, while placebo was administered to 63 subjects. The mean baseline average itch VAS score was approximately 7.9 in both arms. At weeks 2, 4 and 8 , the mean average itch VAS scores decreased to 6.2, 5.5 and 4.4, respectively (serlopitant group), and 7.1, 6.5, 6.1, respectively (placebo group). At weeks 4 and 8 , there was a statistically significantly greater decrease from baseline in pruritus intensity (measured by average VAS score) when comparing serlopitant with placebo $(p=0.025$ at week 4 and $p=0.001$ at week 8). Unfortunately, a phase II trial on serlopitant in CP of unknown origin, and two phase III trials on serlopitant in chronic prurigo, have all failed to meet their primary endpoints regarding pruritus alleviation [62, 63]. Moreover, the ATOMIK study revealed that serlopitant failed to provide additional benefit over placebo in managing pruritus in the course of AD [64]. In 2020, Pariser et al. [65] reported the results of a phase II, randomized, double-blind, placebo-controlled trial among patients with mild-to-moderate psoriasis. Serlopitant $(5 \mathrm{mg} /$ day, starting with a loading dose of $15 \mathrm{mg} /$ day on the first day) or placebo were administered to 102 patients each. At week 8, 33.3\% of patients treated with serlopitant achieved a 4-point improvement from baseline (assessed with WI-NRS), compared with $21.1 \%$ in patients treated with placebo $(p=0.028)$. Additionally, $20.8 \%$ of patients treated with serlopitant achieved a 4-point improvement from baseline on the WI-NRS at week 4 (compared with $11.5 \%$ of patients treated with placebo; $p=0.039$ ). A preliminary study on serlopitant in epidermolysis bullosa (mainly recessive dystrophic type; $n=14$ ) revealed no benefit over placebo in terms of itch reduction or wound size at week 8 [66]. A study involving a larger group of participants is ongoing [67].

\subsection{Tradipitant}

A phase II study on the effectiveness of tradipitant (VLY$686)$ in managing pruritus in the course of $\mathrm{AD}(n=168)$ revealed promising results [68]. In the subsequent phase III study (EPIONE), the primary endpoint was not met in the overall study population $(n=341)$ [69], whereas the EPIONE2 study $(n=200)$ is ongoing [70].

\subsection{Orvepitant}

Finally, a randomised, placebo-controlled, phase II trial evaluated orvepitant in patients $(n=44)$ experiencing severe pruritus caused by EGFRIs, revealing no benefits over placebo [71].

\section{Biologic Drugs}

Biologics are large molecules targeting specific proteins implicated in immune-mediated diseases. In dermatology, the approved therapies alter T-cell activation and differentiation, block cytokines or eliminate pathogenic B cells. Depending on their mechanism of action, biologic medications have been used for a variety of dermatologic indications, mainly psoriasis and AD [72]. Cytokines are 'messenger' proteins, which mediate a series of cellular functions, including immune cell recruitment, activation and differentiation [73]. It has been long known that cytokines create part of the immune system and modulate both adaptive and innate immune responses. They have also been identified as modulators of pain and neurogenic inflammation [74]. Additionally, they can act on resident skin cells, including keratinocytes, Langerhans cells, endothelial cells, fibroblasts and mast cells [75]. In recent years, a considerable amount of proof regarding cytokines playing a role in pruritus has been presented, substantiating the use of targeted therapies with biologics for several chronic inflammatory dermatoses.

\subsection{Interleukin (IL)-4 and IL-13}

Both interleukin (IL)-4 and IL-13 are cytokines produced by T-helper $2\left(\mathrm{Th}_{2}\right)$ cells and play an important role in the development of AD. Their expression correlated with IL-31 levels in the skin biopsies of patients with AD [76]. Additionally, the studies on murine model in atopic-like mice indicated that IL-4 could play a significant role in inflammation and pruritus of $\mathrm{AD}$ patients [77].

\subsubsection{Dupilumab}

Dupilumab is a commercialized monoclonal antibody (mAb) against the IL-4 receptor- $\alpha$ (IL-4R $\alpha$ ) subunit, blocking 
IL-4 and IL-13 signaling [78]. Several randomized trials have been performed on the efficacy of dupilumab in patients with moderate to severe $\mathrm{AD}$, enabling its registration for this indication [79-86]. All the studies confirmed the efficacy of dupilumab in terms of improvement of skin lesions and alleviation of pruritus. Dupilumab was generally well-tolerated and had a placebo-like safety profile. A representative phase III report recounted the SOLO 1 and SOLO 2 trials ( $n=671$ and $n=708$, respectively) [81]. At week 16, an improvement of at least 3-4 points in the peak pruritus NRS score was significantly more common among patients receiving dupilumab than patients receiving placebo $(p<0.001)$. A meta-analysis of 1505 patients with moderate to severe $\mathrm{AD}$ revealed that dupilumab started to unveil its antipruritic properties by days 2 and 5 in adults and adolescents, respectively [87]. The response increased over time and was sustained until the end of the studies (up to 1 year). Recent papers have also reported on 31 patients receiving dupilumab due to chronic prurigo [88-93]. The majority of patients experienced significant pruritus reduction starting to unfold within 4 weeks, followed by more gradual flattening or disappearance of lesions within several months of the initiation of therapy. Furthermore, dupilumab established its efficacy in case reports regarding patients with bullous pemphigoid (BP) [94, 95], chronic refractory pruritus [96] and UP [97]. Clinical trials on the use of dupilumab in chronic spontaneous and cholinergic urticaria are in progress [98, 99].

\subsubsection{Lebrikizumab}

Lebrikizumab is an anti-IL-13 humanized $\mathrm{mAb}$ that binds specifically to soluble IL-13 with high affinity and blocks subsequent signaling [100]. In a recent phase IIb randomized, double-blind study, AD patients received subcutaneous injections of lebrikizumab in different dosages, i.e. $125 \mathrm{mg}$ every 4 weeks ( $250 \mathrm{mg}$ loading dose; $n=73$ ), $250 \mathrm{mg}$ every 4 weeks (500 mg loading dose; $n=80$ ) or $250 \mathrm{mg}$ every 2 weeks (500 mg loading dose at baseline and week $2 ; n=75$ ), while 52 patients received placebo. At week 16, the mean NRS pruritus score percentage changes were $-35.9 \%,-49.6 \%,-60.6 \%$, and $4.3 \%$ of patients, respectively $(p=0.05, p<0.001$ and $p<0.001$ compared with placebo, respectively) [101].

\subsubsection{Tralokinumab}

Tralokinumab is a sole anti-IL-13 human mAb that prevents binding of IL-13 to its receptor [102]. The efficacy and safety of tralokinumab in patients with $\mathrm{AD}$ was evaluated in a phase IIb, double-blind, randomized study. The decrease in pruritus assessed with NRS at week 12 was statistically significantly greater than in the placebo group for all dosing regimens ( $p=0.04$ for the $45 \mathrm{mg}$ dose; $p=0.002$ for the $300 \mathrm{mg}$ dose). Notably, the decrease began from the first week and was maintained until the end of the observation period [103]. Trials are currently being undertaken on the use of tralokinumab in $\mathrm{AD}$, its interaction with other drugs and its combination with topical corticosteroids [104-106].

\subsection{IL-17}

The IL-17 family consists of six cytokines (17A-17F) and five receptors (17RA-17RE). IL-17A is an inflammatory cytokine produced by $\mathrm{Th}_{17}$ cells $[107,108]$. It is commonly associated with autoimmune diseases, cancer progression and pathoimmunology [109]. There is wide evidence suggesting its role in the pathogenesis of psoriasis. IL-17 acts on a variety of cells, including keratinocytes, to stimulate the production of a number of molecules known to be elevated in psoriasis lesions (cytokines, chemokines, $\beta$-defensins) [110]. Additionally, the expression of IL-17 in skin biopsies is significantly elevated in lesional skin of patients with psoriasis [110].

\subsubsection{Secukinumab}

Secukinumab is a human mAb selectively neutralizing IL17A and has been shown to be effective in the treatment of psoriasis. In two representative, phase III, double-blind, randomized studies (FIXTURE and ERASURE) [111] regarding the use of secukinumab in psoriatic patients $(n=1306$ and $n=738$, respectively), a significant antipruritic response was observed at week 12 according to the Psoriasis Symptom Diary $(p<0.001$ compared with placebo and etanercept). Thaci et al. [112] evaluated the use of secukinumab and ustekinumab and exhibited a significantly greater decrease of itch (NRS) at week 16 in patients treated with secukinumab ( -5.0 vs. $-4.6 ; p=0.0053$ ). Two phase II clinical trials on the role of secukinumab in AD treatment are currently underway $[113,114]$.

\subsubsection{Ixekizumab}

Ixekizumab is a high-affinity, humanized $\mathrm{mAb}$ that targets IL-17A [115]. In their analysis of two phase III studies, Yosipovitch et al. [116] established that a large number of psoriatic patients, regardless of baseline itch severity, achieved a clinically meaningful reduction in itch severity preceding Psoriasis Area Severity Index (PASI 90) responses. Ixekizumab also significantly reduced pruritus associated with genital psoriasis, with a rapid onset of action unfolding within the first 2 weeks of therapy $[117,118]$. 


\subsubsection{Brodalumab}

Brodalumab is a human $\mathrm{mAb}$ that targets the IL-17A receptor and blocks the IL-17 pathway [119]. In the study by Gottlieb et al. [120], the Psoriasis Symptom Inventory (PSI) itch item score was significantly improved with both brodalumab $140 \mathrm{mg}$ and $210 \mathrm{mg}$ versus placebo starting at week 2 (30.5\% and 36.1\%, respectively, vs. $7.8 \%$; $p<0.001)$. Additionally, brodalumab induced a more rapid antipruritic response when compared with ustekinumab.

\subsection{IL-23}

IL-23 is a proinflammatory cytokine consisting of two subunits (p19 and p40) and plays an important role in the pathogenesis of psoriasis [121]. It stimulates proliferation of the $\mathrm{Th}_{17}$ lymphocyte population, subsequently producing IL-17A and other proinflammatory cytokines [122].

\subsubsection{Ustekinumab}

Ustekinumab is a human mAb that targets the shared $\mathrm{p} 40$ subunit of the proinflammatory IL-12 and IL-23 cytokines. Its efficacy and safety has been demonstrated in the treatment of psoriasis $[123,124]$. In the study by Reich et al. [123], both ustekinumab $(n=166)$ and ixekizumab $(n=136)$ provided itch alleviation in terms of NRS reduction at week 24. However, patients who experienced at least a 4-point improvement from baseline NRS were more common in the ixekizumab group (85.5\% vs. $72.1 \%$; $p=0.018$ ).

\subsubsection{Risankizumab}

Risankizumab is a human monoclonal immunoglobulin (Ig) $\mathrm{G}$ antibody that binds with high affinity to the p19 subunit of IL-23 [124]. When compared with ustekinumab $(n=40)$, patients receiving risankizumab $(n=126)$ were more likely to experience PASI 90 improvement at week 12 (40\% vs. $77 \%$; $p<0.001)$, as well as in terms of pruritus (assessed by patients' assessment of itch).

\subsubsection{Guselkumab}

Guselkumab is a human $\operatorname{IgG} 1 \lambda$ mAb that binds to the p19 subunit of IL-23 [125]. The efficacy and safety of guselkumab treatment for psoriasis was demonstrated in three phase III trials (VOYAGE 1, VOYAGE 2, NAVIGATE) [126-128]. Furthermore, Papp et al. [129] revealed that patients receiving guselkumab $(n=249)$ experienced higher improvement of itch severity (assessed using the Psoriasis Symptoms and Signs Diary) than in the placebo $(n=129)$ and adalimumab $(n=274)$ groups $(p<0.001)$.

\subsubsection{Tildrakizumab}

Tildrakizumab is a humanized $\operatorname{IgG} 1 \kappa \mathrm{mAB}$ that also selectively binds to the p19 subunit of IL-23 [130]. Treatment with subcutaneous tildrakizumab was studied in two phase III, double-blind, randomized trials in psoriasis (reSURFACE 1 and reSURFACE 2 [131]) and proved statistically efficacious compared with placebo and etanercept in terms of PASI improvement. Unfortunately, the aforementioned studies did not directly report on pruritus outcomes. Nevertheless, among currently active clinical trials on the use of tildrakizumab in psoriasis, there are several that will assess the severity of itch with NRS or VAS [132-136], eventually bringing important insight into the actual antipruritic effect of tildrakizumab.

\subsection{IL-31}

IL-31 is a member of the IL- 6 family and its role in the pathogenesis of pruritus has long been studied. It is involved mainly in $\mathrm{Th}_{2}$ lymphocyte-associated inflammation and does not directly induce pruritus, rather contributing to the itch sensation in inflamed skin [137]. The functional IL-31 receptor (IL-31R) consists of two subunits-IL-31RA and the oncostatin $M$ receptor- $\beta$ (OSMR $\beta$ ). As IL-31 targets dorsal root ganglia in the spinal cord, keratinocytes, eosinophils, mast cells and basophils [138], it is associated with pleomorphic effects associated with pruritus and the chronic inflammatory process in the skin. Increased levels of IL-31 have been reported in itchy dermatoses such as AD, chronic prurigo, mycosis fungoides, $\mathrm{BP}$ and dermatitis herpetiformis [138].

\subsubsection{Nemolizumab}

Nemolizumab is a humanized mAb against IL-31R, which could alleviate pruritus through IL-31 signaling inhibition [139]. A phase II, randomized, double-blind trial among 211 patients with $\mathrm{AD}$ receiving nemolizumab revealed that the active groups were more prone to report pruritus improvement (assessed by VAS) when compared with placebo ( $n=53 ; p=0.002$ in the $0.1 \mathrm{mg} / \mathrm{kg}$ group, and $p<0.001$ in the 0.5 and $2.0 \mathrm{mg} / \mathrm{kg}$ groups) [139]. Another phase II study recounted that nemolizumab significantly reduced pruritus and the severity of skin lesions in patients with moderate to severe chronic prurigo [140]; however, it was also associated with AEs, including gastrointestinal (diarrhea and abdominal pain) and musculoskeletal symptoms.

\subsubsection{Vixarelimab}

Vixarelimab (KPL-716) is a mAB against OSMR $\beta$. It does not directly block IL-31, however it interferes with IL-31 
signaling and has proved effective in decreasing pruritus in AD [141]. It is now being studied in a phase II study on chronic pruritic diseases (LP, lichen simplex chronicus, chronic idiopathic pruritus, plaque psoriasis and chronic idiopathic urticaria) [142], and promising results regarding chronic prurigo have been announced recently [143].

\subsection{Immunoglobulin E}

Ligelizumab is a high-affinity humanized $\operatorname{IgG} 1 \kappa \mathrm{mAb}$ targeting free IgE, basophil FceRI and surface IgE [144]. It inhibits exocytosis from basophils and mast cells, and generation of mediators and cytokines, thereby attenuating allergic responses. In a recent phase IIb trial, ligelizumab was instigated in patients with chronic spontaneous urticaria [145]. At week 12, ligelizumab provided complete control of urticarial flares in $30 \%, 51 \%$, and $42 \%$ of patients (at doses of 24,72 and $240 \mathrm{mg}$ administered every 4 weeks, respectively), in contrast to $26 \%$ of patients treated with another IgE antagonist (omalizumab $300 \mathrm{mg}$ every 4 weeks) and $0 \%$ of patients in the placebo group. Moreover, the weekly Itch Severity Score (ISS7) of 0 at week 12 was achieved by $40 \%, 48 \%$ and $42 \%$ of patients receiving ligelizumab, respectively, compared with only $26 \%$ of patients in the omalizumab group. Ligelizumab was well tolerated, with upper respiratory tract infections and headaches constituting the main AEs.

\section{Janus Kinase Inhibitors}

One of the newly identified targets for dermatological treatment are JAKs, which belong to the group of cytoplasmic tyrosine kinases. When activated by various cytokines, colony-stimulating factors, and hormones, JAKs phosphorylate signal transducer and activator of transcription (STAT) factors and affect expression of specific genes [146], e.g. those associated with inflammatory cytokines and growth factors. JAKs contribute to inflammatory diseases, such as rheumatoid arthritis or inflammatory bowel diseases, however certain dermatologic conditions could also benefit from JAK inhibition [147]. There is growing evidence regarding the safety and efficacy of the use of JAK inhibitors in psoriasis, $\mathrm{AD}$, alopecia areata and vitiligo [148].

\subsection{Ruxolitinib}

Ruxolitinib is a JAK1/2 inhibitor that has been studied in a phase II, double-blind, randomized study in patients with $\mathrm{AD}$ [149]. The use of ruxolitinib $1.5 \%$ cream twice daily led to $42.5 \%$ of patients experiencing minimal clinically important differences in pruritus within $36 \mathrm{~h}$ of treatment (13.6\% for vehicle; $p=0.01)$. Further clinical trials are ongoing regarding the antipruritic properties of ruxolitinib in AD (both for adults and children) [150-152], LP [153] and chronic cutaneous graft-versus-host disease (cGvHD) [154]. Additionally, systemic administration of ruxolitinib improved pruritus in the course of myeloproliferative neoplasms (polycythemia vera, essential thrombocytopenia and myelofibrosis) [155-157].

\subsection{Baricitinib}

Baricitinib is another JAK1/2 inhibitor administered orally [158] and is currently under investigation in several clinical trials in adults and children with AD [159-162]. Its effectiveness in AD was confirmed in one phase II [163] and two phase III studies [158]. An improvement in pruritus was achieved within 1 week in the $4 \mathrm{mg}$ /day group and within 2 weeks in the $2 \mathrm{mg} /$ day group [158]. Moreover, in a phase IIb randomized study among psoriatic patients, all baricitinib treatment groups reported significantly greater mean changes than placebo in the WI-NRS at week 12 [164].

\subsection{Tofacitinib}

Tofacitinib preferably binds to JAK1 and JAK3, with functional selectivity over JAK2 [165]. Oral tofacitinib demonstrated antipruritic properties in several psoriasis studies [166-171] and CP of unknown origin in patients with rheumatoid arthritis [172], whereas its topical preparation proved effective in both AD [173] and psoriasis [174].

\subsection{Abrocitinib}

Oral abrocitinib is a selective JAK1 inhibitor with proven efficacy from a phase II, double-blind, randomized study $(n=267)$ for the treatment of AD in adults [175]. Recently, two clinical trials (JADE Mono-1 and JADE Mono-2) have confirmed its antipruritic properties in adolescent and adult patients with $\mathrm{AD}$ ( $n=387$ and $n=391$, respectively) compared with placebo [176, 177]. Moreover, in March 2020, the results of the JADE Compare study [178] were announced, which demonstrated the superiority of abrocitinib (200 mg/ day) over dupilumab in achieving a clinically significant reduction in pruritus severity (at least a 4-point reduction assessed using the Peak Pruritus NRS) at week 2 [179].

\subsection{Upadacitinib}

Upadacitinib is another oral selective JAK1 inhibitor that warrants its improved benefit-to-risk ratio [180]. GuttmanYassky et al. [181] reported on a phase IIb randomized trial in adult patients with moderate to severe $\mathrm{AD}$ receiving upadacitinib monotherapy $(n=126)$ or placebo $(n=41)$. Regardless of dose, patients receiving upadacitinib experienced 
quick improvement in pruritus (within 1 week), and the improvement in pruritus at week 16 was significantly higher in the active groups than in the placebo group $(p<0.001$ for the 30 and $15 \mathrm{mg} /$ day doses, and $p<0.01$ for the $7.5 \mathrm{mg} / \mathrm{day}$ dose). Several trials are in progress [182-184], including the evaluation of upadacitinib versus dupilumab [185] and safety aspects in the pediatric population with AD [186].

\subsection{Delgocitinib}

Delgocitinib is a new JAK inhibitor specific for JAK1, JAK2, JAK3 and tyrosine kinase 2 (TYK-2) [187]. Treatment with topical delgocitinib proved effective for chronic hand eczema in a phase IIb, double-blind, randomized study [188]. At week 8, there was no difference between the active and placebo groups in terms of the 'no itching' status $(p=0.09)$. However, a greater proportion of patients with a baseline itch NRS score $>4$ points experienced at least a 4-point reduction in NRS at week 8 compared with placebo (55\% vs. $24 \%$; $p=0.029)$. Three recent reports have currently elucidated delgocitinib as an effective modality in reducing pruritus in the course of $\mathrm{AD}$, including pediatric subjects [189-191].

\section{Phosphodiesterase-4 Inhibitors}

PDE-4 is an intracellular enzyme that takes apart cyclic adenosine monophosphate (cAMP). PDE-4 inhibition leads to increased cAMP levels, subsequently suppressing the production of various cytokines involved in the inflammatory processes of AD (e.g. IL-4, IL-5, IL-13) [192].

Crisaborole is a small molecule containing boron atom that targets PDE-4 [193]. Its effectiveness in AD was observed among adults and children [193, 194]. Patients receiving crisaborole $2 \%$ ointment experienced pruritus relief at day 29 (assessed using a 4-point scale; an expected score of 0 or 1 point and $\mathrm{a} \geq 1$-point reduction from baseline) more commonly than patients receiving vehicle (63\% vs. 53\%; $p=0.002$ ) [194]. Furthermore, crisaborole was more likely to provide antipruritic response at the earliest assessment on day $2(34.3 \%$ vs. $27.3 \% ; p=0.013)$ and early improvement of pruritus at day $6(56.6 \%$ vs. $39.5 \% ; p<0.001)$ than vehicle [195], thereby emphasizing its rapid mode of action.

\section{Tropomyosin-Receptor Kinase A Inhibitors}

Tropomyosin receptor kinase A (TrkA) is a surface transmembrane tyrosine kinase serving as a receptor for NGF and contributes to the development of psoriasis and pruritic response [196]. NGF stimulates histamine secretion from mast cells and sensitization of peripheral sensory nerve terminals.

Pegcantratinib (CT327/SNA-120) was utilized topically in patients with psoriasis and revealed no benefit over placebo in terms of improvement of cutaneous lesions [197]. However, among a subgroup of patients $(n=108)$ initially complaining of moderate pruritus (VAS $\geq 40 \mathrm{~mm}$ ), pegcantratinib $0.05 \%, 0.1 \%$ and $0.5 \%$ provided mean VAS reductions of $37.1,31.5$ and $36.4 \mathrm{~mm}$, respectively, whereas patients receiving placebo experienced only a $16.1 \mathrm{~mm}$ improvement $(p=0.0067$, $p=0.0523$, and $p=0.0124$, respectively). Conversely, another study $(n=208)$ among psoriatic patients reported clinical improvement in terms of psoriatic lesions but no significant reduction of itch when compared with vehicle (4.2 points according to WI-NRS vs. 3.9 points; $p=0.362$ ) [198]. Recently, Zhong et al. [196] explored the inhibitory properties against the NGF/TrkA pathway of cucurbitacins, which are tetracyclic triterpenes derived from plants (especially the Cucurbitaceae family). The authors implied cucurbitacins could be potential precursors of successful antipruritics in the future.

\section{Ileal Bile Acid Transporter Inhibitors}

$\mathrm{CP}$ is an important and common symptom in patients with PBC, primary sclerosing cholangitis (PSC) or Allagile syndrome. The complex pathogenesis involves, among others, the role of bile salts, opioids, serotonin, lysophosphatidic acid and autotaxin [199-202]. IBAT inhibitors block the SLC10A2 transporter, decreasing reabsorption of bile acids in the terminal ileum and subsequently reducing enterohepatic recirculation and stimulating fecal excretion of bile acids [203, 204]. These effects are similar to the effects achieved by partial external biliary diversion surgical procedures that interrupt the circulation of bile acids and reduce pruritus.

In a phase II, randomized, crossover trial on linerixibat (GSK2330672; $n=22$ ), patients with PBC experienced significant pruritus improvement over placebo [205]. Another study reported on $10 \mathrm{PBC}$ patients who were administered odevixibat (A4250) for 4 weeks, of whom four finished the study per protocol and achieved excellent alleviation of pruritus [206]. Two further studies on maralixabat (SHP625) used for 13 weeks in patients with PBC $(n=66)$ and children with Allagile syndrome $(n=37)$ revealed alleviation of pruritus in the active groups, but the differences over the placebo groups did not reach statistical significance [203, 204]. 


\section{Aryl Hydrocarbon Receptor Agonists}

AhR, also termed dioxin receptor, is a ligand-activated transcription factor expressed in all types of skin cells, which binds to environmental polyaromatic hydrocarbons and dioxins, eventually causing oxidative stress [207, 208]. There is high expression of AhR in all epidermal cells and fibroblasts of the skin [209]. AhR maintains skin barrier integrity, regulates innate and adaptive immune responses, impacts the balance of $\mathrm{Th}_{17}$ and T-regulatory cells and is associated with photoaging and skin carcinogenesis [210-212]. In general, the AhR signaling pathway is linked to several conditions, mainly non-melanoma skin cancers, melanoma, $\mathrm{AD}$, psoriasis, chloracne or vitiligo [207].

Tapinarof (GSK2894512) is a naturally derived stilbene particle that activates AhR, subsequently inducing the expression of barrier genes in keratinocytes and downregulating the $\mathrm{Th}_{17}$ pathway, thereby possessing the potential for alleviating symptoms of AD [211]. In a recent phase II study, 247 patients with $\mathrm{AD}$ were randomized to receive tapinar of cream or vehicle for 12 weeks [213]. In addition to achieving improvement in terms of the Investigator's Global Assessment (IGA) and Eczema Area and Severity Index (EASI), pruritus also improved (according to NRS), with differences between the active and vehicle arms beginning to unveil at week 2 .

\section{Histamine $\mathrm{H}_{\mathbf{4}}$ Receptor Antagonists}

Histamine is regarded as a classic mediator of itch and is released from mast cells during inflammation or stimulation by allergens. It induces itch by interacting with histamine receptors on unmyelinated C-fibers [214]. Currently, four types of receptors are described $\left(\mathrm{H}_{1} \mathrm{R}, \mathrm{H}_{2} \mathrm{R}, \mathrm{H}_{3} \mathrm{R}\right.$ and $\left.\mathrm{H}_{4} \mathrm{R}\right)$, with $\mathrm{H}_{1} \mathrm{R}$ being the most commonly targeted in clinical practice. $\mathrm{H}_{4} \mathrm{R}$ was cloned in 2000 and is chiefly expressed on hematopoietic cells, possessing relevant properties associated with the activation of mast cells, eosinophils, monocytes, dendritic cells and T lymphocytes [215]. It is an important component influencing the $\mathrm{Th}_{2}$ lymphocyte response, with its stimulation resulting in induction of IL-31 and the signal transduction molecules activator protein 1 (AP-1) [216]. Experimental studies on mice have demonstrated that an $\mathrm{H}_{4} \mathrm{R}$ antagonist (JNJ-7777120) reduces dermal inflammation and pruritus via reducing tissue cytokines and chemokines and inhibiting chemotaxis $[217,218]$. The relevance of the $\mathrm{Th}_{2}$ milieu in the development of $\mathrm{AD}$ warranted the possibility of experimenting with $\mathrm{H}_{4} \mathrm{R}$ antagonists in the human population with this common condition. A phase II, randomized, double-blind study evaluated an $\mathrm{H}_{4} \mathrm{R}$ antagonist (JNJ-39758979) in patients with moderate AD
[219]. Despite alleviation of pruritus, the study was ended prematurely due to safety concerns (agranulocytosis in 2 of 88 patients).

In a recent study [220], another $\mathrm{H}_{4} \mathrm{R}$ antagonist (adriforant; ZPL-3893787) was instigated orally in $65 \mathrm{AD}$ patients, while 33 patients received placebo. Overall, the baseline maximal pruritus intensity measured by NRS was approximately 7.3 points. At week 8 , pruritus was reduced by 3 points in the active group and by 2.7 points in the placebo group $(p=0.25)$. The beneficial effect on itch reduction might have been partially confounded by the use of rescue medication (such as topical corticosteroids) in the placebo group. Moreover, the EASI excoriation subscore (an indirect indicator of pruritus) revealed improvement from baseline at week $8(p<0.05)$. Further studies (ZEST and ZESTExt) among AD patients are ongoing [221, 222].

\section{Miscellaneous Modalities}

Based on anecdotal reports in humans, the potential utility of various complementary treatment modalities remains to be elucidated more clearly in the future, e.g. regarding the $755 \mathrm{~nm}$ alexandrite laser, botulinum toxin, acupuncture, transcranial magnetic stimulation, extracorporeal shockwave therapy, massage with violet oil, positive verbal suggestions or music therapy [223-231].

Additionally, experimental evidence points towards the growing importance of certain itch-associated signaling pathways that may be targeted in the near future, including the spinal $\alpha 2 / \alpha 3 \mathrm{GABA}_{\mathrm{A}}$ receptors, bovine adrenal medulla (BAM) 8-22 and the Mrgpr, sodium channels $\left(\mathrm{Na}_{\mathrm{V}} 1.7, \mathrm{Na}_{\mathrm{V}} 1.8, \mathrm{Na}_{\mathrm{V}} 1.9\right)$, natriuretic peptides (BNP) and their receptors (NPR-1), gastrin-releasing peptide receptor (GRPR), PAR2 and CCL2/CCR2 [232-242].

\section{Conclusions}

Regardless of the cause, patients with $\mathrm{CP}$ will benefit from the continuously increasing armamentarium of novel therapies. To a large extent, the expected progress is based on the flourishing data on CP pathophysiology, but, in the era of evidence-based medicine, another crucial factor (conscientious planning and execution of clinical trials) has to be taken into account. Thereby, therapeutic success, safety and economic issues will be maintained in real-life settings.

Author Contributions RR and PK participated in the literature search, data analysis, manuscript creation and revision. JCS participated in the data analysis, manuscript creation and revision. 


\section{Compliance with Ethical Standards}

Funding No funding was received to assist in the preparation of this manuscript.

Conflict of interest Jacek C. Szepietowski reports personal fees from Abbvie, Leo Pharma, Novartis, Pierre-Fabre, Menlo Therapeutics, Sienna Biopharmaceuticals, Trevi, Janssen, Sunfarm, Elli-Lilly, BerlinChemie Mennarini, Merck, Regeneron, Sanofi-Genzyme, Amgen, Boehringer Ingelheim, Galapagos, InflaRX, Pfizer, UCB, Incyte and Helm. Radomir Reszke and Piotr Krajewski have no conflicts of interest to declare.

Open Access This article is licensed under a Creative Commons Attribution-NonCommercial 4.0 International License, which permits any non-commercial use, sharing, adaptation, distribution and reproduction in any medium or format, as long as you give appropriate credit to the original author(s) and the source, provide a link to the Creative Commons licence, and indicate if changes were made. The images or other third party material in this article are included in the article's Creative Commons licence, unless indicated otherwise in a credit line to the material. If material is not included in the article's Creative Commons licence and your intended use is not permitted by statutory regulation or exceeds the permitted use, you will need to obtain permission directly from the copyright holder. To view a copy of this licence, visit http://creativecommons.org/licenses/by-nc/4.0/.

\section{References}

1. Ständer S, Weisshaar E, Mettang T, et al. Clinical classification of itch: a position paper of the International Forum for the Study of Itch. Acta Derm Venereol. 2007;87:291-4.

2. Weisshaar E, Szepietowski JC, Dalgard FJ, et al. European S2k guideline on chronic pruritus. Acta Derm Venereol. 2019;99:469-506. https://doi.org/10.2340/00015555-3164.

3. Amatya B, Wennersten G, Nordlind K. Patients' perspective of pruritus in chronic plaque psoriasis: a questionnaire-based study. J Eur Acad Dermatol Venereol. 2008;22:822-6.

4. Dalgard FJ, Svensson $\AA$, Halvorsen JA, et al. Itch and mental health in dermatological patients across Europe: a cross-sectional study in 13 countries. J Investig Dermatol. 2020;140:568-73.

5. Dimitrov D, Matusiak $€$, Szepietowski JC. Stigmatization in Arabic psoriatic patients in the United Arab Emirates-a cross sectional study. Postepy Dermatol Alergol. 2019;36:425-30.

6. Yosipovitch G, Rosen JD, Hashimoto T. Itch: from mechanism to (novel) therapeutic approaches. J Allergy Clin Immunol. 2018;142:1375-90. https://doi.org/10.1016/j.jaci.2018.09.005.

7. Yosipovitch G, Berger T, Fassett MS. Neuroimmune interactions in chronic itch of atopic dermatitis. J Eur Acad Dermatol Venereol. 2020;34:239-50. https://doi.org/10.1111/jdv.15973.

8. Benarroch EE. Endogenous opioid systems: current concepts and clinical correlations. Neurology. 2012;79:807-14.

9. Henriksen G, Willoch F. Imaging of opioid receptors in the central nervous system. Brain. 2008;131:1171-96.

10. Phan NQ, Lotts T, Antal A, et al. Systemic kappa opioid receptor agonists in the treatment of chronic pruritus: a literature review. Acta Derm Venereol. 2012;92:555-60.

11. Reich A, Ständer S, Szepietowski JC. Drug-induced pruritus: a review. Acta Derm Venereol. 2009;89:236-44.
12. Ko MC, Naughton NN. An experimental itch model in monkeys: characterization of intrathecal morphine-induced scratching and antinociception. Anesthesiology. 2000;92:795-805.

13. Ko MC, Song MS, Edwards T, et al. The role of central mu opioid receptors in opioid-induced itch in primates. J Pharmacol Exp Ther. 2004;310:169-76.

14. Ko MC, Husbands SM. Effects of atypical kappa-opioid receptor agonists on intrathecal morphine-induced itch and analgesia in primates. J Pharmacol Exp Ther. 2009;328:193-200.

15. Tominaga M, Ogawa $\mathrm{H}$, Takamori K. Possible roles of epidermal opioid systems in pruritus of atopic dermatitis. J Investig Dermatol. 2007;127:2228-35.

16. Taneda K, Tominaga M, Negi O, et al. Evaluation of epidermal nerve density and opioid receptor levels in psoriatic itch. Br J Dermatol. 2011;165:277-84.

17. Kupczyk P, Reich A, Hołysz M, et al. Opioid receptors in psoriatic skin: relationship with itch. Acta Derm Venereol. 2017;97:564-70.

18. Wieczorek A, Krajewski P, Kozioł-Gałczyńska M, et al. Opioid receptors expression in the skin of hemodialysis patients suffering from uremic pruritus. J Eur Acad Dermatol Venereol. 2020. https://doi.org/10.1111/jdv.16360.

19. Bergasa NV, Alling DW, Talbot TL, et al. Effects of naloxone infusions in patients with the pruritus of cholestasis. A double-blind, randomized, controlled trial. Ann Intern Med. 1995;123:161-7.

20. Okutomi T, Saito M, Mochizuki J, et al. Prophylactic epidural naloxone reduces the incidence and severity of neuraxial fentanyl-induced pruritus during labour analgesia in primiparous parturients. Can J Anaesth. 2003;50:961-2.

21. Joshi GG, Thakur BS, Sircar S, et al. Role of intravenous naloxone in severe pruritus of acute cholestasis. Indian J Gastroenterol. 2009;28:180-2.

22. Peer G, Kivity S, Agami O, et al. Randomised crossover trial of naltrexone in uraemic pruritus. Lancet. 1996;348:1552-4.

23. Metze D, Reimann S, Beissert S, et al. Efficacy and safety of naltrexone, an oral opiate receptor antagonist, in the treatment of pruritus in internal and dermatological diseases. J Am Acad Dermatol. 1999;41:533-9.

24. Brune A, Metze D, Luger TA, et al. Antipruritic therapy with the oral opioid receptor antagonist naltrexone. Open, nonplacebo controlled administration in 133 patients. Hautarzt. 2004;55:1130-6.

25. Frech T, Novak K, Revelo MP, et al. Low-dose naltrexone for pruritus in systemic sclerosis. Int J Rheumatol. 2011;2011:804296. https://doi.org/10.1155/2011/804296.

26. Banerji D, Fox M, Seleznick M, et al. J Allergy Clin Immunol. 1988;81:252.

27. Bergasa NV, Alling DW, Talbot TL, et al. Oral nalmefene therapy reduces scratching activity due to the pruritus of cholestasis: a controlled study. J Am Acad Dermatol. 1999;41:431-4.

28. Dunteman E, Karanikolas M, Filos KS. Transnasal butorphanol for the treatment of opioid-induced pruritus unresponsive to antihistamines. J Pain Symptom Manag. 1996;12:255-60.

29. Dawn AG, Yosipovitch G. Butorphanol for treatment of intractable pruritus. J Am Acad Dermatol. 2006;54:527-31.

30. Somrat C, Oranuch K, Ketchada U, et al. Optimal dose of nalbuphine for treatment of intrathecal-morphine induced pruritus after caesarean section. J Obstet Gynaecol Res. 1999;25:209-13.

31. Charuluxananan S, Kyokong O, Somboonviboon W, et al. Nalbuphine versus ondansetron for prevention of intrathecal morphine-induced pruritus after cesarean delivery. Anesth Analg. 2003;96:1789-93.

32. Hawi A, Alcorn H Jr, Berg J, et al. Pharmacokinetics of nalbuphine hydrochloride extended release tablets in hemodialysis 
patients with exploratory effect on pruritus. BMC Nephrol. 2015;16:47. https://doi.org/10.1186/s12882-015-0043-3.

33. Mathur VS, Kumar J, Crawford PW, et al. A multicenter, randomized, double-blind, placebo-controlled trial of nalbuphine ER tablets for uremic pruritus. Am J Nephrol. 2017;46:450-8.

34. Trevi Therapeutics Ltd. Trevi therapeutics announces positive results from phase 2 trial in Prurigo Nodularis. https://www.trevi therapeutics.com/wp-content/uploads/2019/01/TreviPNToplineD ataPR.10_.13_.16_.FINAL_pdf.

35. Trevi Therapeutics Ltd. PRISM study_pruritus relief through itch scratch modulation (PRISM). ClinicalTrials.gov. https://clini caltrials.gov/show/NCT03497975.

36. Wikström B, Gellert R, Ladefoged SD, et al. Kappa-opioid system in uremic pruritus: multicenter, randomized, doubleblind, placebo-controlled clinical studies. J Am Soc Nephrol. 2005;16:3742-7.

37. Kumagai H, Ebata T, Takamori K, et al. Effect of a novel kappareceptor agonist, nalfurafine hydrochloride, on severe itch in 337 haemodialysis patients: a PHASE III, randomized, double-blind, placebo-controlled study. Nephrol Dial Transplant. 2010;25:1251-7.

38. Kumagai H, Ebata T, Takamori K, et al. Efficacy and safety of a novel $\mathrm{\kappa}$-agonist for managing intractable pruritus in dialysis patients. Am J Nephrol. 2012;36:175-83.

39. Ueno Y, Mori A, Yanagita T. One year long-term study on abuse liability of nalfurafine in hemodialysis patients. Int J Clin Pharmacol Ther. 2013;51:823-31.

40. Nakamoto H, Oh T, Shimamura N, et al. Nalfurafine hydrochloride for refractory pruritus in peritoneal dialysis patients: a phase III, multi-institutional, non-controlled, open-label trial. Ren Replace Ther. 2017;3:51.

41. Kozono H, Yoshitani H, Nakano R. Post-marketing surveillance study of the safety and efficacy of nalfurafine hydrochloride (Remitch ${ }^{\circledR}$ capsules $2.5 \mu \mathrm{g}$ ) in 3762 hemodialysis patients with intractable pruritus. Int J Nephrol Renovasc Dis. 2018;11:9-24.

42. Kamimura K, Yokoo T, Kamimura H, et al. Long-term efficacy and safety of nalfurafine hydrochloride on pruritus in chronic liver disease patients: patient-reported outcome based analyses. PLoS One. 2017;12:e0178991. https://doi.org/10.1371/journ al.pone.0178991.

43. Kumada H, Miyakawa H, Muramatsu T, et al. Efficacy of nalfurafine hydrochloride in patients with chronic liver disease with refractory pruritus: a randomized, double-blind trial. Hepatol Res. 2017;47:972-82.

44. Akuta N, Kumada H, Fujiyama S, et al. Recurrence rates of pruritus after the stop of nalfurafine hydrochloride in chronic liver disease: preliminary prospective confirmatory trial. Hepatol Res. 2018;48:810-3.

45. Albert-Vartanian A, Boyd MR, Hall AL, et al. Will peripherally restricted kappa-opioid receptor agonists (pKORAs) relieve pain with less opioid adverse effects and abuse potential? J Clin Pharm Ther. 2016;41:371-82.

46. Fishbane S, Mathur V, Germain MJ, et al. Randomized controlled trial of difelikefalin for chronic pruritus in hemodialysis patients. Kidney Int Rep. 2020;5(5):600-10. https://doi.org/10.1016/j. ekir.2020.01.006.

47. Fishbane S, Jamal A, Munera C, et al. A phase 3 trial of difelikefalin in hemodialysis patients with pruritus. N Engl J Med. 2020;382:222-32.

48. Cara Therapeutics, Inc. A study to evaluate the safety and efficacy of CR845 in chronic kidney disease patients with moderateto-severe pruritus. ClinicalTrials.gov. https://clinicaltrials.gov/ show/NCT03617536.

49. Cara Therapeutics, Inc., Study to evaluate the safety and efficacy of oral CR845 (difelikefalin) in patients with primary biliary cholangitis (PBC) and moderate-to-severe pruritus. ClinicalTrials.gov. https://clinicaltrials.gov/show/NCT03995212.

50. Lotts T, Ständer S. Research in practice: substance $P$ antagonism in chronic pruritus. J Dtsch Dermatol Ges. 2014;12:557-9.

51. Ständer S, Yosipovitch G. Substance P and neurokinin 1 receptor are new targets for the treatment of chronic pruritus. Br J Dermatol. 2019;181:932-8.

52. Nattkemper LA, Tey HL, Valdes-Rodriguez R, et al. The genetics of chronic itch: gene expression in the skin of patients with atopic dermatitis and psoriasis with severe itch. J Investig Dermatol. 2018;138:1311-7.

53. US FDA. Emend prescribing information. https://www.acces sdata.fda.gov/drugsatfda_docs/label/2015/207865lbl.pdf.

54. Duval A, Dubertret L. Aprepitant as an antipruritic agent? N Engl J Med. 2009;361:1415-6.

55. Vincenzi B, Tonini G, Santini D. Aprepitant for erlotinib-induced pruritus. N Engl J Med. 2010;363:397-8.

56. Vincenzi B, Fratto ME, Santini D, et al. Aprepitant against pruritus in patients with solid tumours. Support Care Cancer. 2010;18:1229-30.

57. Santini D, Vincenzi B, Guida FM, et al. Aprepitant for management of severe pruritus related to biological cancer treatments: a pilot study. Lancet Oncol. 2012;13:1020-4.

58. Ständer S, Siepmann D, Herrgott I, et al. Targeting the neurokinin receptor 1 with aprepitant: a novel antipruritic strategy. PLoS One. 2010;5:e10968. https://doi.org/10.1371/journal.pone.00109 68.

59. Agelopoulos K, Rülander F, Dangelmaier J, et al. Neurokinin 1 receptor antagonists exhibit peripheral effects in prurigo nodularis including reduced ERK1/2 activation. J Eur Acad Dermatol Venereol. 2019;33:2371-9.

60. Yosipovitch G, Ständer S, Kerby MB, et al. Serlopitant for the treatment of chronic pruritus: results of a randomized, multicenter, placebo-controlled phase 2 clinical trial. J Am Acad Dermatol. 2018;78(882-91):e10. https://doi.org/10.1016/j. jaad.2018.02.030.

61. Ständer S, Kwon P, Hirman J, et al. Serlopitant reduced pruritus in patients with prurigo nodularis in a phase 2, randomized, placebo-controlled trial. J Am Acad Dermatol. 2019;80:1395-402.

62. Menlo Therapeutics Announces Results from Phase 2 Trial of Serlopitant in Patients with Chronic Pruritus of Unknown Origin. http://ir.menlotherapeutics.com/news-releases/news-release-detai 1s/menlo-therapeutics-announces-results-phase-2-trial-serlopitan $\mathrm{t}-0$.

63. Menlo Therapeutics Announces Results from Two Phase 3 Clinical Trials of Serlopitant for the Treatment of Pruritus Associated with Prurigo Nodularis. http://ir.menlotherapeutics.com/ news-releases/news-release-details/menlo-therapeutics-annou nces-results-two-phase-3-clinical-trials.

64. Menlon Therapeutics Inc., Study of the efficacy, safety, and tolerability of serlopitant for pruritus (itch) in atopic dermatitis (ATOMIK). ClinicalTrials.gov. https://clinicaltrials.gov/show/ NCT02975206.

65. Pariser DM, Bagel J, Lebwohl M, et al. Serlopitant for psoriatic pruritus: a phase 2 randomized, double-blind, placebo-controlled clinical trial. J Am Acad Dermatol. 2020;82:1314-20. https://doi. org/10.1016/j.jaad.2020.01.056.

66. Chiou AS, Choi S, Barriga M, et al. Phase 2 trial of a neurokinin-1 receptor antagonist for the treatment of chronic itch in patients with epidermolysis bullosa: a randomized clinical trial. J Am Acad Dermatol. 2020;82:1415-21. https://doi.org/10.1016/j. jaad.2019.09.014.

67. Stanford University. A neurokinin-1 receptor antagonist for the treatment of pruritus in patients with epidermolysis bullosa. ClinicalTrials.gov. https://clinicaltrials.gov/show/NCT03836001. 
68. Heitman A, Xiao C, Cho Y, et al. Tradipitant improves worst itch and disease severity in patients with chronic pruritus related to atopic dermatitis. J Am Acad Dermatol. 2018;79:AB300.

69. Vanda Reports results from the EPIONE study of Tradipitant in the treatment of Pruritus in Atopic Dermatitis. https://vanda pharmaceuticalsinc.gcs-web.com/node/13961/pdf.

70. Evaluating the effects of tradipitant vs. placebo in atopic dermatitis (EPIONE2). ClinicalTrials.gov. https://clinicaltrials.gov/ show/NCT04140695.

71. Vincenzi B, Trower M, Duggal A, et al. Neurokinin-1 antagonist orvepitant for EGFRI-induced pruritus in patients with cancer: a randomised, placebo-controlled phase II trial. BMJ Open. 2020;10:e030114. https://doi.org/10.1136/bmjopen-2019-03011 4.

72. Fathi R, Armstrong AW. The role of biologic therapies in dermatology. Med Clin N Am. 2015;99:1183-94.

73. Storan ER, O'Gorman SM, McDonald ID, Steinhoff M. Role of cytokines and chemokines in itch. Handb Exp Pharmacol. 2015;226:163-76. https://doi.org/10.1007/978-3-662-44605-8_9.

74. Zhang JM, An J. Cytokines, inflammation, and pain. Int Anesthesiol Clin. 2007;45:27-37. https://doi.org/10.1097/AIA.0b013 e318034194e.

75. Cevikbas F, Kempkes C, Buhl T, et al. Role of interleukin-31 and Oncostatin $\mathrm{M}$ in itch and neuroimmune communication. In: Carstens E, Akiyama T, editors. Itch: mechanisms and treatment. Boca Raton: CRC Press; 2014. p. 237-56.

76. Neis MM, Peters B, Dreuw A, et al. Enhanced expression levels of IL-31 correlate with IL-4 and IL-13 in atopic and allergic contact dermatitis. J Allergy Clin Immunol. 2006;118:930-7.

77. Cevikbas F, Wang X, Akiyama T, et al. A sensory neuronexpressed IL-31 receptor mediates T helper cell-dependent itch: involvement of TRPV1 and TRPA1. J Allergy Clin Immunol. 2014;133:448-60.

78. Hamilton JD, Suarez-Farinas M, Dhingra N, et al. Dupilumab improves the molecular signature in skin of patients with moderate-to-severe atopic dermatitis. J Allergy Clin Immunol. 2014;134:1293-300.

79. Beck LA, Thaci D, Hamilton JD, et al. Dupilumab treatment in adults with moderate-to-severe atopic dermatitis. $\mathrm{N}$ Engl $\mathrm{J}$ Med. 2014;371:130-9.

80. Simpson EL, Gadkari A, Worm M, et al. Dupilumab therapy provides clinically meaningful improvement in patient-reported outcomes (PROs): a phase IIb, randomized, placebo-controlled, clinical trial in adult patients with moderate to severe atopic dermatitis (AD). J Am Acad Dermatol. 2016;75:506-15.

81. Simpson EL, Bieber T, Guttman-Yassky E, et al. Two phase 3 trials of dupilumab versus placebo in atopic dermatitis. N Engl J Med. 2016;375:2335-48.

82. Thaci D, Simpson EL, Deleuran M, et al. Efficacy and safety of dupilumab monotherapy in adults with moderate-to-severe atopic dermatitis: a pooled analysis of two phase 3 randomized trials (LIBERTY AD SOLO 1 and LIBERTY AD SOLO 2). J Dermatol Sci. 2019;94:266-75.

83. Blauvelt A, de Bruin-Weller M, Gooderham M, et al. Longterm management of moderate-to-severe atopic dermatitis with dupilumab and concomitant topical corticosteroids (LIBERTY AD CHRONOS): a 1-year, randomised, double-blinded, placebo-controlled, phase 3 trial. Lancet. 2017;389:2287-303.

84. De Bruin-Weller M, Thaçi D, Smith CH, et al. Dupilumab with concomitant topical corticosteroid treatment in adults with atopic dermatitis with an inadequate response or intolerance to ciclosporin A or when this treatment is medically inadvisable: a placebo-controlled, randomized phase III clinical trial (LIBERTY AD CAFÉ). Br J Dermatol. 2018;178:1083-101.

85. Simpson EL, Paller AS, Siegfried EC, et al. Efficacy and safety of dupilumab in adolescents with uncontrolled moderate to severe atopic dermatitis: a phase 3 randomized clinical trial. JAMA Dermatol. 2019;156(1):44-56. https://doi.org/10.1001/ jamadermatol.2019.3336.

86. Deleuran M, Thaçi D, Beck LA, et al. Dupilumab shows longterm safety and efficacy in patients with moderate to severe atopic dermatitis enrolled in a phase 3 open-label extension study. J Am Acad Dermatol. 2020;82:377-88. https://doi. org/10.1016/j.jaad.2019.07.074.

87. Silverberg JI, Yosipovitch G, Simpson EL, et al. Dupilumab treatment results in early and sustained improvements in itch in adolescents and adults with moderate to severe atopic dermatitis: Analysis of the randomized phase 3 studies SOLO 1 and SOLO 2, AD ADOL, and CHRONOS. J Am Acad Dermatol. 2020;82:1328-36. https://doi.org/10.1016/j.jaad.2020.02.060.

88. Beck KM, Yang EJ, Sekhon S, et al. Dupilumab treatment for generalized prurigo nodularis. JAMA Dermatol. 2019;155:118-20.

89. Rambhia PH, Levitt JO. Recalcitrant prurigo nodularis treated successfully with dupilumab. JAAD Case Rep. 2019;5:471-3.

90. Mollanazar NK, Elgash M, Weaver L, et al. Reduced itch associated with dupilumab treatment in 4 patients with prurigo nodularis. JAMA Dermatol. 2019;155:121-2.

91. Almustafa ZZ, Weller K, Autenrieth J, et al. Dupilumab in treatment of chronic prurigo: a case series and literature review. Acta Derm Venereol. 2019;99:905-6.

92. Holm JG, Agner T, Sand C, et al. Dupilumab for prurigo nodularis: case series and review of the literature. Dermatol Ther. 2020;33(2):e13222. https://doi.org/10.1111/dth.13222.

93. Calugareanu A, Jachiet M, Tauber M, et al. Effectiveness and safety of dupilumab for the treatment of prurigo nodularis in a French multicenter adult cohort of 16 patients. J Eur Acad Dermatol Venereol. 2020;34:e74-6. https://doi.org/10.1111/ jdv.15957.

94. Kaye A, Gordon SC, Deverapalli SC, et al. Dupilumab for the treatment of recalcitrant bullous pemphigoid. JAMA Dermatol. 2018;154:1225-6.

95. Seidman JS, Eichenfield DZ, Orme CM. Dupilumab for bullous pemphigoid with intractable pruritus. Dermatol Online J. 2019;25:13030/qt25q9w6r9.

96. Zhai LL, Savage KT, Qiu CC, et al. Chronic pruritus responding to dupilumab-a case series. Medicines (Basel). 2019;6(3):72. https://doi.org/10.3390/medicines6030072.

97. Silverberg JI, Brieva J. A successful case of dupilumab treatment for severe uremic pruritus. JAAD Case Rep. 2019;5:339-41.

98. Charite University. Cholinergic urticaria - efficacy of dupilumab (CHED). ClinicalTrials.gov. https://clinicaltrials.gov/show/ NCT03749148.

99. Charite University. Dupilumab in chronic spontaneous urticaria (DUPICSU). ClinicalTrials.gov. https://clinicaltrials.gov/show/ NCT03749135.

100. Simpson EL, Flohr C, Eichenfield LF, et al. Efficacy and safety of lebrikizumab (an anti-IL-13 monoclonal antibody) in adults with moderate-to-severe atopic dermatitis inadequately controlled by topical corticosteroids: a randomized, placebo-controlled phase II trial (TREBLE). J Am Acad Dermatol. 2018;78:863-71. https ://doi.org/10.1016/j.jaad.2018.01.017.

101. Guttman-Yassky E, Blauvelt A, Eichenfield LF, et al. Efficacy and safety of lebrikizumab, a high-affinity interleukin 13 inhibitor, in adults with moderate to severe atopic dermatitis: a phase $2 \mathrm{~b}$ randomized clinical trial. JAMA Dermatol. 2020;156(4):411-20. https://doi.org/10.1001/jamadermatol.2020.0079.

102. May RD, Monk PD, Cohen ES, et al. Preclinical development of CAT-354, an IL-13 neutralizing antibody, for the treatment of severe uncontrolled asthma. Br J Pharmacol. 2012;166:177-93. 
103. Wollenberg A, Howell MD, Guttman-Yassky E, et al. Treatment of atopic dermatitis with tralokinumab, an anti-IL-13 mAb. J Allergy Clin Immunol. 2019;143:135-41.

104. LEO Pharma. Drug-drug interaction trial with tralokinumab in moderate to severe atopic dermatitis - ECZTRA 4. ClinicalTrials.gov. https://clinicaltrials.gov/show/NCT03556592.

105. LEO Pharma. Tralokinumab in combination with topical corticosteroids in subjects with severe atopic dermatitis who are not adequately controlled with or have contraindications to oral cyclosporine A (ECZTRA 7). ClinicalTrials.gov. https://clinicaltr ials.gov/show/NCT03761537.

106. LEO Pharma. Tralokinumab monotherapy for adolescent subjects with moderate to severe atopic dermatitis-ECZTRA 6 (ECZema TRAlokinumab Trial no. 6). ClinicalTrials.gov. https ://clinicaltrials.gov/show/NCT03526861.

107. Girolomoni G, Mrowietz U, Paul C. Psoriasis: rationale for targeting interleukin-17. Br J Dermatol. 2012;167:717-24.

108. Kirkham BW, Kavanaugh A, Reich K. Interleukin-17A: a unique pathway in immune-mediated diseases: psoriasis, psoriatic arthritis and rheumatoid arthritis. Immunology. 2014;141:133-42.

109. Amatya N, Garg AV, Gaffen SL. IL-17 Signaling: The Yin and the Yang. Trends Immunol. 2017;38:310-22.

110. Martin DA, Towne JE, Kricorian G, et al. The emerging role of IL-17 in the pathogenesis of psoriasis: preclinical and clinical findings. J Investig Dermatol. 2013;133:17-26.

111. Langley RG, Elewski BE, Lebwohl M, et al. Secukinumab in plaque psoriasis - results of two phase 3 trials. N Engl J Med. 2014;371:326-38.

112. Thaci D, Blauvelt A, Reich K, et al. Secukinumab is superior to ustekinumab in clearing skin of subjects with moderate to severe plaque psoriasis: CLEAR, a randomized controlled trial. J Am Acad Dermatol. 2015;73:400-9.

113. GWT-TUD GmbH. Investigation of efficacy of secukinumab in patients with moderate to severe atopic dermatitis (Secu_-in AD). ClinicalTrials.gov. https://clinicaltrials.gov/show/NCT03 568136.

114. Icahn School of Medicine at Mount Sinai. Secukinumab for treatment of atopic dermatitis. ClinicalTrials.gov. https://clini caltrials.gov/show/NCT02594098.

115. Liu L, Lu J, Allan BW, et al. Generation and characterization of ixekizumab, a humanized monoclonal antibody that neutralizes interleukin-17A. J Inflamm Res. 2016;9:39-50. https://doi. org/10.2147/JIR.S100940.

116. Yosipovitch G, Reich A, Steinhoff M, et al. Impact of ixekizumab treatment on itch and psoriasis area and severity index in patients with moderate-to-severe plaque psoriasis: an integrated analysis of two phase III randomized studies. Dermatol Ther (Heidelb). 2018;8:621-37.

117. Ryan C, Menter A, Guenther L, et al. Efficacy and safety of ixekizumab in a randomized, double-blinded, placebo-controlled phase IIIb study of patients with moderate-to-severe genital psoriasis. Br J Dermatol. 2018;179:844-52. https://doi.org/10.1111/ bjd.16736.

118. Yosipovitch G, Foley P, Ryan C, et al. Ixekizumab improved patient-reported genital psoriasis symptoms and impact of symptoms on sexual activity vs placebo in a randomized, double-blind study. J Sex Med. 2018;15:1645-52. https://doi.org/10.1016/j. jsxm.2018.09.004.

119. Papp KA, Leonardi C, Menter A, et al. Brodalumab, an antiinterleukin-17-receptor antibody for psoriasis. N Engl J Med. 2012;366:1181-9.

120. Gottlieb AB, Gordon K, Hsu S, et al. Improvement in itch and other psoriasis symptoms with brodalumab in phase 3 randomized controlled trials. J Eur Acad Dermatol Venereol. 2018;32:1305-13.
121. Di Meglio P, Nestle FO. The role of IL-23 in the immunopathogenesis of psoriasis. F1000 Biol Rep. 2010;2:40. https://doi. org/10.3410/b2-40.

122. Di Cesare A, Di Meglio P, Nestle FO. The IL-23/Th17 axis in the immunopathogenesis of psoriasis. J Investig Dermatol. 2009;129:1339-50.

123. Reich K, Pinter A, Lacour JP, et al. Comparison of ixekizumab with ustekinumab in moderate-to-severe psoriasis: 24-week results from IXORA-S, a phase III study. Br J Dermatol. 2017; 177:1014-23.

124. Papp KA, Blauvelt A, Bukhalo M, et al. Risankizumab versus ustekinumab for moderate-to-severe plaque psoriasis. N Engl J Med. 2017;376:1551-60.

125. Nogueira M, Torres T. Guselkumab for the treatment of psoriasis-evidence to date. Drugs Context. 2019;8:212594. https:// doi.org/10.7573/dic.212594.

126. Blauvelt A, Papp KA, Griffiths CE, et al. Efficacy and safety of guselkumab, an anti-interleukin-23 monoclonal antibody, compared with adalimumab for the continuous treatment of patients with moderate to severe psoriasis: results from the phase III, double-blinded, placebo- and active comparator-controlled VOYAGE 1 trial. J Am Acad Dermatol. 2017;76:405-17.

127. Reich K, Armstrong AW, Foley P, et al. Efficacy and safety of guselkumab, an anti-interleukin-23 monoclonal antibody, compared with adalimumab for the treatment of patients with moderate to severe psoriasis with randomized withdrawal and retreatment: results from the phase III, double-blind, placeboand active comparator-controlled VOYAGE 2 trial. J Am Acad Dermatol. 2017;76:418-31.

128. Langley RG, Tsai TF, Flavin S, et al. Efficacy and safety of guselkumab in patients with psoriasis who have an inadequate response to ustekinumab: results of the randomized, double-blind, phase III NAVIGATE trial. Br J Dermatol. 2018;178:114-23.

129. Papp KA, Blauvelt A, Kimball AB, et al. Patient-reported symptoms and signs of moderate-to-severe psoriasis treated with guselkumab or adalimumab: results from the randomized VOYAGE 1 trial. J Eur Acad Dermatol Venereol. 2018;32:1515-22.

130. Papp K, Thaçi D, Reich K, et al. Tildrakizumab (MK-3222), an anti-interleukin-23p19 monoclonal antibody, improves psoriasis in a phase IIb randomized placebo-controlled trial. Br J Dermatol. 2015;173:930-9.

131. Reich K, Papp K, Blauvelt A, et al. Tildrakizumab versus placebo or etanercept for chronic plaque psoriasis (reSURFACE 1 and reSURFACE 2): results from two randomised controlled, phase 3 trials. Lancet. 2017;390:276-88.

132. Sun Pharma Global FZE. A real world study evaluating the longterm quality of life of tildrakizumab in adult patients with psoriasis. ClinicalTrials.gov. https://clinicaltrials.gov/show/NCT03 718299.

133. Almirall, S.A. Efficacy and safety of tildrakizumab in participants with moderate-to-severe chronic plaque psoriasis who are non-responders to dimethyl fumarate therapy (TRANSITION). ClinicalTrials.gov. https://clinicaltrials.gov/show/NCT0426361 0 .

134. Almirall, S.A. Observational study of tildrakizumab in patients with moderate to severe plaque psoriasis in routine clinical practice (SAIL). ClinicalTrials.gov. https://clinicaltrials.gov/show/ NCT04203693.

135. Almirall, S.A. Efficacy and safety of tildrakizumab 100 milligrams (mg) in participants with moderate-severe chronic plaque psoriasis and its impact on their quality of life (TRIBUTE). ClinicalTrials.gov. https://clinicaltrials.gov/show/NCT04229836. 
136. Sun Pharma Global FZE. Efficacy and safety of tildrakizumab in the treatment of scalp psoriasi. ClinicalTrials.gov. https://clini caltrials.gov/show/NCT03897088.

137. Hawro T, Saluja R, Weller K, et al. Interleukin-31 does not induce immediate itch in atopic dermatitis patients and healthy controls after skin challenge. Allergy. 2014;69:113-7.

138. Bagci IS, Ruzicka T. IL-31: a new key player in dermatology and beyond. J Allergy Clin Immunol. 2018;141:858-66.

139. Ruzicka T, Hanifin JM, Furue M, et al. Anti-interleukin-31 receptor A antibody for atopic dermatitis. N Engl J Med. 2017;376:826-35.

140. Stander S, Yosipovitch G, Legat FJ, et al. Trial of nemolizumab in moderate-to-severe prurigo nodularis. N Engl J Med. 2020;382:706-16.

141. Mikhak Z, Bissonnette R, Siri D, et al. KPL-716, anti-Oncostatin $M$ receptor beta antibody, reduced pruritus in atopic dermatitis. J Investig Dermatol. 2019;139:S96. https://doi.org/10.1016/j. jid.2019.03.636.

142. Kiniksa Pharmaceuticals Ltd. A study to assess the efficacy, safety and tolerability of KPL-716 in reducing pruritus in chronic pruritic diseases. ClinicalTrials.gov. https://clinicaltrials.gov/ show/NCT03858634.

143. Kiniksa Announces Phase 2 Clinical Trial of Vixarelimab (KPL716) in Prurigo Nodularis Meets Primary Efficacy Endpoint. https://www.kiniksa.com/wp-content/uploads/2020/04/KPL71 6.PN_.P2a.PR_.Final_.pdf.

144. Arm JP, Bottoli I, Skerjanec A, et al. Pharmacokinetics, pharmacodynamics and safety of QGE031 (ligelizumab), a novel highaffinity anti-IgE antibody, in atopic subjects. Clin Exp Allergy. 2014;44:1371-85.

145. Maurer M, Giménez-Arnau AM, Sussman G, et al. Ligelizumab for chronic spontaneous urticaria. N Engl J Med. 2019;381:1321-32.

146. O'Shea JJ, Schwartz DM, Villarino AV, et al. The JAK-STAT pathway: impact on human disease and therapeutic intervention. Annu Rev Med. 2015;66:311-28.

147. Shreberk-Hassidim R, Ramot Y, Zlotogorski A. Janus kinase inhibitors in dermatology: a systematic review. J Am Acad Dermatol. 2017;76:745-53. https://doi.org/10.1016/j. jaad.2016.12.004.

148. Damsky W, King BA. JAK inhibitors in dermatology: the promise of a new drug class. J Am Acad Dermatol. 2017;76:736-44.

149. Kim BS, Sun K, Papp K, et al. Effects of ruxolitinib cream on pruritus and quality of life in atopic dermatitis: results from a phase 2, randomized, dose-ranging, vehicle- and active-controlled study. J Am Acad Dermatol. 2020;82:1305-13. https:// doi.org/10.1016/j.jaad.2020.02.009.

150. Incyte Corporation. TRuE AD2 - an efficacy and safety study of ruxolitinib cream in adolescents and adults with atopic dermatitis. ClinicalTrials.gov. https://clinicaltrials.gov/show/ NCT03745651.

151. Incyte Corporation. TRuE AD1 - an efficacy and safety study of ruxolitinib cream in adolescents and adults with atopic dermatitis. ClinicalTrials.gov. https://clinicaltrials.gov/show/ NCT03745638.

152. Incyte Corporation. A pharmacokinetic study of ruxolitinib phosphate cream in pediatric subjects with atopic dermatitis. ClinicalTrials.gov. https://clinicaltrials.gov/show/NCT03 257644.

153. Aaron R. Mangold. Topical ruxolitinib lichen planus. ClinicalTrials.gov. https://clinicaltrials.gov/show/NCT03697460.

154. National Institute of Arthritis and Musculoskeletal and Skin Diseases (NIAMS). Topical ruxolitinib for cutaneous chronic graft versus host disease (cGvHD). ClinicalTrials.gov. https://clinicaltr ials.gov/show/NCT03395340.
155. Vannucchi AM, Kiladjian JJ, Griesshammer M, et al. Ruxolitinib versus standard therapy for the treatment of polycythemia vera. N Engl J Med. 2015;372:426-35.

156. Verstovsek S, Passamonti F, Rambaldi A, et al. Ruxolitinib for essential thrombocythemia refractory to or intolerant of hydroxyurea: long-term phase 2 study results. Blood. 2017;130:1768-71.

157. Vaa BE, Tefferi A, Gangat N, et al. Pruritus in primary myelofibrosis: management options in the era of JAK inhibitors. Ann Hematol. 2016;95:1185-9.

158. Simpson EL, Lacour JP, Spelman L, et al. Baricitinib in patients with moderate-to-severe atopic dermatitis and inadequate response to topical corticosteroids: results from two randomized monotherapy phase III trials. Br J Dermatol. 2020. https://doi. org/10.1111/bjd.18898.

159. Eli Lilly and Company. A study of baricitinib (LY3009104) in adult participants with moderate to severe atopic dermatitis (BREEZE-AD5). ClinicalTrials.gov. https://clinicaltrials.gov/ show/NCT03435081.

160. Eli Lilly and Company. A study of long-term baricitinib (LY3009104) therapy in atopic dermatitis (BREEZE-AD3). ClinicalTrials.gov. https://clinicaltrials.gov/show/NCT03334435.

161. Eli Lilly and Company. A study of baricitinib (LY3009104) in participants with moderate to severe atopic dermatitis (BREEZEAD6). ClinicalTrials.gov. https://clinicaltrials.gov/show/NCT03 559270.

162. Eli Lilly and Company. A study of baricitinib (LY3009104) in children and adolescents with atopic dermatitis (BREEZE-ADPEDS). ClinicalTrials.gov. https://clinicaltrials.gov/show/NCT03 952559.

163. Guttman-Yassky E, Silverberg JI, Nemoto O, et al. Baricitinib in adult patients with moderate-to-severe atopic dermatitis: a phase 2 parallel, double-blinded, randomized placebo-controlled multiple-dose study. J Am Acad Dermatol. 2019;80:913-21. https:// doi.org/10.1016/j.jaad.2018.01.018.

164. Papp KA, Menter MA, Raman M, et al. A randomized phase 2b trial of baricitinib, an oral Janus kinase (JAK) 1/JAK2 inhibitor, in patients with moderate-to-severe psoriasis. Br J Dermatol. 2016;174:1266-76.

165. Hodge JA, Kawabata TT, Krishnaswami S, et al. The mechanism of action of tofacitinib - an oral Janus kinase inhibitor for the treatment of rheumatoid arthritis. Clin Exp Rheumatol. 2016;34:318-28.

166. Bushmakin AG, Mamolo C, Cappelleri JC, et al. The relationship between pruritus and the clinical signs of psoriasis in patients receiving tofacitinib. J Dermatol Treat. 2015;26:19-22.

167. Feldman SR, Thaçi D, Gooderham M, et al. Tofacitinib improves pruritus and health-related quality of life up to 52 weeks: results from 2 randomized phase III trials in patients with moderate to severe plaque psoriasis. J Am Acad Dermatol. 2016;75(116270):e3. https://doi.org/10.1016/j.jaad.2016.07.040.

168. Papp KA, Krueger JG, Feldman SR, et al. Tofacitinib, an oral Janus kinase inhibitor, for the treatment of chronic plaque psoriasis: long-term efficacy and safety results from 2 randomized phase-III studies and 1 open-label long-term extension study. J Am Acad Dermatol. 2016;74:841-50.

169. Valenzuela F, Paul C, Mallbris L, et al. Tofacitinib versus etanercept or placebo in patients with moderate to severe chronic plaque psoriasis: patient-reported outcomes from a Phase 3 study. J Eur Acad Dermatol Venereol. 2016;30:1753-9.

170. Griffiths CE, Vender R, Sofen H, et al. Effect of tofacitinib withdrawal and re-treatment on patient-reported outcomes: results from a Phase 3 study in patients with moderate to severe chronic plaque psoriasis. J Eur Acad Dermatol Venereol. 2017:31:323-32.

171. Ständer S, Luger T, Cappelleri JC, et al. Validation of the Itch severity item as a measurement tool for pruritus in patients with 
psoriasis: results from a phase 3 tofacitinib program. Acta Derm Venereol. 2018;98:340-5.

172. Wang F, Morris C, Bodet ND, et al. Treatment of refractory chronic pruritus of unknown origin with tofacitinib in patients with rheumatoid arthritis. JAMA Dermatol. 2019. https://doi. org/10.1001/jamadermatol.2019.2804.

173. Bissonnette R, Papp KA, Poulin Y, et al. Topical tofacitinib for atopic dermatitis: a phase IIa randomized trial. Br J Dermatol. 2016;175:902-11.

174. Papp KA, Bissonnette R, Gooderham M, et al. Treatment of plaque psoriasis with an ointment formulation of the Janus kinase inhibitor, tofacitinib: a phase $2 \mathrm{~b}$ randomized clinical trial. BMC Dermatol. 2016;16:15. https://doi.org/10.1186/s1289 5-016-0051-4.

175. Gooderham MJ, Forman SB, Bissonnette R, et al. Efficacy and safety of oral janus kinase 1 inhibitor abrocitinib for patients with atopic dermatitis: a phase 2 randomized clinical trial. JAMA Dermatol. 2019. https://doi.org/10.1001/jamadermatol.2019.2855.

176. Pfizer. Study to evaluate efficacy and safety of PF-04965842 in subjects aged 12 years and older with moderate to severe atopic dermatitis (JADE Mono-1). ClinicalTrial.gov. https://clinicaltr ials.gov/show/NCT03349060.

177. Pfizer. Study evaluating efficacy and safety of PF-04965842 in subjects aged 12 years and older with moderate to severe atopic dermatitis (JADE Mono-2). ClinicalTrial.gov. https://clinicaltr ials.gov/show/NCT03575871.

178. Pfizer. Study evaluating efficacy and safety of PF-04965842 and dupilumab in adult subjects with moderate to severe atopic dermatitis on background topical therapy (JADE Compare). ClinicalTrial.gov. https://clinicaltrials.gov/show/NCT03720470.

179. Pfizer Announces Positive Top-Line Results from Phase 3 Study of Investigational Oral JAK1 Candidate, Abrocitinib (PF04965842), in Patients Aged 12 and Older with Moderate to Severe Atopic Dermatitis. https://investors.pfizer.com/investornews/press-release-details/2020/Pfizer-Announces-Positive-TopLine-Results-from-Third-Phase-3-Trial-of-Abrocitinib-for-Moderate-to-Severe-Atopic-Dermatitis-Which-Showed-Improvements-in-Skin-Clearance-Disease-Extent-and-Severity-and-Itch/ default.aspx.

180. Parmentier JM, Voss J, Graff C, et al. In vitro and in vivo characterization of the JAK1 selectivity of upadacitinib (ABT-494). BMC Rheumatol. 2018;2:23. https://doi.org/10.1186/s4192 7-018-0031-x.

181. Guttman-Yassky E, Thaci D, Pangan AL, et al. Upadacitinib in adults with moderate to severe atopic dermatitis: 16-week results from a randomized, placebo-controlled trial. J Allergy Clin Immunol. 2020;145:877-84.

182. AbbVie. A study to evaluate upadacitinib in adolescent and adult subjects with moderate to severe atopic dermatitis (Measure Up 2). ClinicalTrials.gov. https://clinicaltrials.gov/show/NCT03 607422 .

183. AbbVie. Evaluation of upadacitinib in adolescent and adult patients with moderate to severe atopic dermatitis (eczema) (Measure Up 1). ClinicalTrials.gov. https://clinicaltrials.gov/ show/NCT03569293.

184. AbbVie. A study to evaluate upadacitinib in combination with topical corticosteroids in adolescent and adult participants with moderate to severe atopic dermatitis (AD Up). ClinicalTrials.gov. https://clinicaltrials.gov/show/NCT03568318.

185. AbbVie. A study to compare safety and efficacy of upadacitinib to dupilumab in adult participants with moderate to severe atopic dermatitis (Heads Up). ClinicalTrials.gov. https://clinicaltrials. gov/show/NCT03738397.

186. AbbVie. A study to evaluate the pharmacokinetics, safety and tolerability of upadacitinib in pediatric participants with severe atopic dermatitis. ClinicalTrials.gov. https://clinicaltrials.gov/ show/NCT03646604.

187. Tanimoto A, Ogawa Y, Oki C, et al. Pharmacological properties of JTE-052: a novel potent JAK inhibitor that suppresses various inflammatory responses in vitro and in vivo. Inflamm Res. 2015;64:41-51.

188. Worm M, Bauer A, Elsner P, et al. Efficacy and safety of topical delgocitinib in patients with chronic hand eczema: data from a randomized, double-blind, vehicle-controlled phase IIa study. Br J Dermatol. 2020;182:1103-10.

189. Nakagawa H, Nemoto O, Igarashi A, et al. Delgocitinib ointment, a topical Janus kinase inhibitor, in adult patients with moderate to severe atopic dermatitis: A phase 3, randomized, double-blind, vehicle-controlled study and an open-label, long-term extension study. J Am Acad Dermatol. 2020;82:823-31.

190. Nakagawa H, Nemoto O, Igarashi A, et al. Phase 2 clinical study of delgocitinib ointment in pediatric patients with atopic dermatitis. J Allergy Clin Immunol. 2019;144:1575-83.

191. Nakagawa H, Nemoto O, Igarashi A, et al. Long-term safety and efficacy of delgocitinib ointment, a topical Janus kinase inhibitor, in adult patients with atopic dermatitis. J Dermatol. 2020;47:114-20.

192. Guttman-Yassky E, Hanifin JM, Boguniewicz M, et al. The role of phosphodiesterase 4 in the pathophysiology of atopic dermatitis and the perspective for its inhibition. Exp Dermatol. 2019;28:3-10. https://doi.org/10.1111/exd.13808.

193. Tom WL, Van Syoc M, Chanda S, et al. Pharmacokinetic profile, safety, and tolerability of crisaborole topical ointment, $2 \%$ in adolescents with atopic dermatitis: an open-label phase 2a study. Pediatr Dermatol. 2016;33:150-9. https://doi.org/10.1111/ pde. 12780 .

194. Paller AS, Tom WL, Lebwohl MG, et al. Efficacy and safety of crisaborole ointment, a novel, nonsteroidal phosphodiesterase 4 (PDE4) inhibitor for the topical treatment of atopic dermatitis (AD) in children and adults. J Am Acad Dermatol. 2016;75(494503):e6. https://doi.org/10.1016/j.jaad.2016.05.046.

195. Yosipovitch G, Gold LF, Lebwohl MG, et al. Early Relief of pruritus in atopic dermatitis with crisaborole ointment, a nonsteroidal, phosphodiesterase 4 inhibitor. Acta Derm Venereol. 2018;98:484-9.

196. Zhong Y, Xu H, Zhong Y, et al. Identification and characterization of the Cucurbitacins, a novel class of small-molecule inhibitors of Tropomyosin receptor kinase A. BMC Complement Altern Med. 2019;19:295. https://doi.org/10.1186/s1290 6-019-2709-z.

197. Roblin D, Yosipovitch G, Boyce B, et al. Topical TrkA kinase inhibitor CT327 is an effective, novel therapy for the treatment of pruritus due to psoriasis: results from experimental studies, and efficacy and safety of CT327 in a phase $2 b$ clinical trial in patients with psoriasis. Acta Derm Venereol. 2015;95:542-8.

198. Duffin KC, Ständer S, Draelos Z, et al. SNA-120, a novel topical non-steroidal therapy for psoriasis and associated pruritus that targets the NGF/TrkA pathway: results from a multicentre phase 2b study. 10th World Congress of Itch. 17-19 November 2019; Sydney, NSW. OP15.

199. Herndon JH Jr. Pathophysiology of pruritus associated with elevated bile acid levels in serum. Arch Intern Med. 1972;130:632-7.

200. Ghent CN, Bloomer JR, Klatskin G. Elevations in skin tissue levels of bile acids in human cholestasis: relation to serum levels and to pruritus. Gastroenterology. 1977;73:1125-30.

201. Raderer M, Müller C, Scheithauer W. Ondansetron for pruritus due to cholestasis. N Engl J Med. 1994;330:1540.

202. Kremer AE, Martens JJ, Kulik W, et al. Lysophosphatidic acid is a potential mediator of cholestatic pruritus. Gastroenterology. 2010;139:1008-18. 
203. Shneider BL, Spino C, Kamath BM, et al. Placebo-controlled randomized trial of an intestinal bile salt transport inhibitor for pruritus in alagille syndrome. Hepatol Commun. 2018;2:1184-98.

204. Mayo MJ, Pockros PJ, Jones D, et al. A randomized, controlled, phase 2 study of maralixibat in the treatment of itching associated with primary biliary cholangitis. Hepatol Commun. 2019;3:365-81.

205. Hegade VS, Kendrick SF, Dobbins RL, et al. Effect of ileal bile acid transporter inhibitor GSK2330672 on pruritus in primary biliary cholangitis: a double-blind, randomised, placebo-controlled, crossover, phase 2a study. Lancet. 2017;389:1114-23.

206. Al-Dury S, Wahlström A, Wahlin S, et al. Pilot study with IBAT inhibitor A4250 for the treatment of cholestatic pruritus in primary biliary cholangitis. Sci Rep. 2018;8:6658. https://doi. org/10.1038/s41598-018-25214-0.

207. Napolitano M, Patruno C. Aryl hydrocarbon receptor (AhR) a possible target for the treatment of skin disease. Med Hypotheses. 2018;116:96-100.

208. Furue M, Hashimoto-Hachiya A, Tsuji G. Aryl hydrocarbon receptor in atopic dermatitis and psoriasis. Int J Mol Sci. 2019;20:E5424. https://doi.org/10.3390/ijms20215424.

209. Esser C, Bargen I, Weighardt H, et al. Functions of the aryl hydrocarbon receptor in the skin. Semin Immunopathol. 2013;35:677-91.

210. Haas K, Weighardt H, Deenen R, et al. Aryl hydrocarbon receptor in keratinocytes is essential for murine skin barrier integrity. $\mathbf{J}$ Investig Dermatol. 2016;136:2260-9.

211. Smith SH, Jayawickreme C, Rickard DJ, et al. Tapinarof is a natural AhR agonist that resolves skin inflammation in mice and humans. J Investig Dermatol. 2017;137:2110-9.

212. Vogeley C, Esser C, Tüting T, et al. Role of the aryl hydrocarbon receptor in environmentally induced skin aging and skin carcinogenesis. Int J Mol Sci. 2019;20:E6005. https://doi.org/10.3390/ ijms20236005.

213. Peppers J, Paller AS, Maeda-Chubachi T, et al. A phase 2, randomized dose-finding study of tapinarof (GSK2894512 cream) for the treatment of atopic dermatitis. J Am Acad Dermatol. 2019;80(89-98):e3. https://doi.org/10.1016/j. jaad.2018.06.047.

214. Shim WS, Oh U. Histamine-induced itch and its relationship with pain. Mol Pain. 2008;4:29. https://doi. org/10.1186/1744-8069-4-29.

215. Ohsawa Y, Hirasawa N. The role of histamine H1 and H4 receptors in atopic dermatitis: from basic research to clinical study. Allergol Int. 2014;63:533-42.

216. Gutzmer R, Mommert S, Gschwandtner M, et al. The histamine $\mathrm{H} 4$ receptor is functionally expressed on $\mathrm{T}(\mathrm{H}) 2$ cells. J Allergy Clin Immunol. 2009;123:619-25.

217. Dunford PJ, Williams KN, Desai PJ, et al. Histamine H4 receptor antagonists are superior to traditional antihistamines in the attenuation of experimental pruritus. J Allergy Clin Immunol. 2007;119:176-83.

218. Cowden JM, Zhang M, Dunford PJ, et al. The histamine H4 receptor mediates inflammation and pruritus in Th2-dependent dermal inflammation. J Investig Dermatol. 2010;130:1023-33.

219. Murata Y, Song M, Kikuchi H, et al. Phase 2a, randomized, double-blind, placebo-controlled, multicenter, parallel-group study of a H4 R-antagonist (JNJ-39758979) in Japanese adults with moderate atopic dermatitis. J Dermatol. 2015;42:129-39.

220. Werfel T, Layton G, Yeadon M, et al. Efficacy and safety of the histamine H4 receptor antagonist ZPL-3893787 in patients with atopic dermatitis. J Allergy Clin Immunol. 2019;143(1830 1837):e4. https://doi.org/10.1016/j.jaci.2018.07.047.

221. Novartis Pharmaceuticals. A study to assess the safety and efficacy of ZPL389 in patients with moderate to severe atopic dermatitis. ClinicalTrials.gov. https://clinicaltrials.gov/show/ NCT03517566.

222. Novartis Pharmaceuticals. A study to assess the safety and efficacy of ZPL389 with TCS/TCI in atopic dermatitis patients (ZESTExt). ClinicalTrials.gov. https://clinicaltrials.gov/show/ NCT03948334.

223. Pancar GS, Kalkan G, Eyupoglu O. The effects of $755 \mathrm{~nm}$ alexandrite laser on skin dryness and pruritus. Adv Dermatol Allergol. 2020;37:29-33.

224. Boozalis E, Sheu M, Selph J, et al. Botulinum toxin type A for the treatment of localized recalcitrant chronic pruritus. J Am Acad Dermatol. 2018;78:192-4.

225. Napadow V, Li A, Loggia ML, et al. The brain circuitry mediating antipruritic effects of acupuncture. Cereb Cortex. 2014;24:873-82.

226. Min S, Kim KW, Jung WM, et al. Acupuncture for histamineinduced itch: association with increased parasympathetic tone and connectivity of putamen-midcingulate cortex. Front Neurosci. 2019;13:215. https://doi.org/10.3389/fnins.2019.00215.

227. Jones O, Schindler I, Holle H. Transcranial magnetic stimulation over contralateral primary somatosensory cortex disrupts perception of itch intensity. Exp Dermatol. 2019;28:1380-4. https://doi. org/10.1111/exd.13803.

228. Samhan AF, Abdelhalim NM. Impacts of low-energy extracorporeal shockwave therapy on pain, pruritus, and health-related quality of life in patients with burn: a randomized placebo-controlled study. Burns. 2019;45:1094-101.

229. Khorsand A, Salari R, Noras MR, et al. The effect of massage and topical violet oil on the severity of pruritus and dry skin in hemodialysis patients: a randomized controlled trial. Complement Ther Med. 2019;45:248-53.

230. Meeuwis SH, van Middendorp H, van Laarhoven AIM, et al. Effects of open- and closed-label nocebo and placebo suggestions on itch and itch expectations. Front Psychiatry. 2019;10:436. https://doi.org/10.3389/fpsyt.2019.00436.

231. Demirtas S, Houssais C, Tanniou J, et al. Effectiveness of a music intervention on pruritus: an open randomized prospective study. J Eur Acad Dermatol Venereol. 2019. https://doi.org/10.1111/ jdv.16149.

232. Ralvenius WT, Neumann E, Pagani M, et al. Itch suppression in mice and dogs by modulation of spinal $\alpha 2$ and $\alpha 3$ GABAA receptors. Nat Commun. 2018;9:3230. https://doi.org/10.1038/ s41467-018-05709-0.

233. Sanjel B, Maeng HJ, Shim WS. BAM8-22 and its receptor MRGPRX1 may attribute to cholestatic pruritus. Sci Rep. 2019;9:10888. https://doi.org/10.1038/s41598-019-47267-5.

234. Yu H, Zhao T, Liu S, et al. MRGPRX4 is a bile acid receptor for human cholestatic itch. Elife. 2019;8:e48431. https://doi. org/10.7554/eLife.48431.

235. Salvatierra J, Diaz-Bustamante M, Meixiong J, et al. A disease mutation reveals a role for $\mathrm{NaV} 1.9$ in acute itch. J Clin Investig. 2018;128:5434-47.

236. Kühn H, Kappes L, Wolf $\mathrm{K}$, et al. Complementary roles of murine $\mathrm{NaV} 1.7, \mathrm{NaV} 1.8$ and NaV1.9 in acute itch signalling. Sci Rep. 2020;10:2326. https://doi.org/10.1038/s41598-020-59092 -2 .

237. Solinski HJ, Dranchak P, Oliphant E, et al. Inhibition of natriuretic peptide receptor 1 reduces itch in mice. Sci Transl Med. 2019;11:eaav5464. https://doi.org/10.1126/scitranslmed.aav54 64.

238. Meng J, Chen W, Wang J. Interventions in the B-type natriuretic peptide signalling pathway as a means of controlling chronic itch. Br J Pharmacol. 2020;177:1025-40.

239. Yu MJ, Yao S, Li TT, et al. Dual anti-cancer and anti-itch activity of PD176252 analogues: design, synthesis and biological evaluation. Anticancer Agents Med Chem. 2019;19:992-1001. 
240. Huang Z, Zhou X, Zhang J, et al. Bulleyaconitine A inhibits itch and itch sensitization induced by histamine and chloroquine. Neuroscience. 2020;429:68-77.

241. Barr TP, Garzia C, Guha S, et al. PAR2 pepducin-based suppression of inflammation and itch in atopic dermatitis models. $\mathrm{J}$ Investig Dermatol. 2019;139:412-21.

242. Jiang $\mathrm{H}$, Cui $\mathrm{H}$, Wang $\mathrm{T}$, et al. CCL2/CCR2 signaling elicits itch- and pain-like behavior in a murine model of allergic contact dermatitis. Brain Behav Immun. 2019;80:464-73.

243. Feldman SR, Green L, Kimball AB, et al. Secukinumab improves scalp pain, itching, scaling and quality of life in patients with moderate-to-severe scalp psoriasis. J Dermatol Treat. 2017;28(8):716-21.

244. Yosipovitch G, Soung J, Weiss J, et al. Secukinumab provides rapid relief from itching and pain in patients with moderate-tosevere psoriasis: patient symptom diary data from two phase 3 , randomized, placebo-controlled clinical trials. Acta Derm Venereol. 2019;99:820-1.

245. Leonardi C, Matheson R, Zachariae C, et al. Anti-interleukin-17 monoclonal antibody ixekizumab in chronic plaque psoriasis. $\mathrm{N}$ Engl J Med. 2012;366:1190-9.

246. Griffiths CE, Reich K, Lebwohl M, et al. Comparison of ixekizumab with etanercept or placebo in moderate-to-severe psoriasis (UNCOVER-2 and UNCOVER-3): results from two phase 3 randomised trials. Lancet. 2015;386:541-51.

247. Blauvelt A, Papp K, Gottlieb A, et al. A head-to-head comparison of ixekizumab vs. guselkumab in patients with moderate-tosevere plaque psoriasis: 12-week efficacy, safety and speed of response from a randomized, double-blinded trial. $\mathrm{Br} J$ Dermatol. 2020;182(6):1348-58. https://doi.org/10.1111/bjd.18851.

248. AbbVie. A study to evaluate risankizumab in adult and adolescent subjects with moderate to severe atopic dermatitis. ClinicalTrials.gov. https://clinicaltrials.gov/show/NCT03706040.
249. Thaçi D, Pinter A, Sebastian M, et al. Guselkumab is superior to fumaric acid esters in patients with moderate-to-severe plaque psoriasis who are naive to systemic treatment: results from a randomized, active-comparator-controlled phase IIIb trial (POLARIS). Br J Dermatol. 2019. https://doi.org/10.1111/bjd.18696.

250. Nemoto O, Furue M, Nakagawa $H$, et al. The first trial of CIM331, a humanized antihuman interleukin-31 receptor A antibody, in healthy volunteers and patients with atopic dermatitis to evaluate safety, tolerability and pharmacokinetics of a single dose in a randomized, double-blind, placebo-controlled study. $\mathrm{Br}$ J Dermatol. 2016;174:296-304.

251. Kabashima K, Furue M, Hanifin JM, et al. Nemolizumab in patients with moderate-to-severe atopic dermatitis: randomized, phase II, long-term extension study. J Allergy Clin Immunol. 2018;142(1121-1130):e7. https://doi.org/10.1016/j. jaci.2018.03.018.

252. Silverberg JI, Pinter A, Pulka G, et al. Phase 2B randomized study of nemolizumab in adults with moderate-to-severe atopic dermatitis and severe pruritus. J Allergy Clin Immunol. 2020;145:173-82.

253. Galderma R\&D. Long-term safety and efficacy of nemolizumab with moderate-to-severe atopic dermatitis. ClinicalTrials.gov. https://clinicaltrials.gov/show/NCT03989206.

254. Galderma R\&D. A long-term study of nemolizumab (CD14152) in participants with prurigo nodularis (PN). ClinicalTrials.gov. https://clinicaltrials.gov/show/NCT04204616. 